\title{
IMPACTOS DEL PARAMILITARISMO EN LA REGIÓN URABÁ/CHOCÓ 1998-2006. CLAVES PARA LA LECTURA DE LAS AFECTACIONES COLECTIVAS ${ }^{2}$.
}

\author{
HORIZONTALITY, EXPRESSION, AND SHARED KNOWLEDGE: \\ AN APPROACH ON PSYCHOSOCIAL PROCESSES OF ACCOMPANIMENT TO VICTIMS
}

OF POLITICAL VIOLENCE IN COLOIMBIA.

Recibido: agosto 2011 - Revisado: febrero 2012 - Aceptado: 30 de junio de 2012

Por: Nicolás Espinosa $\mathrm{M}^{1}$.

\section{RESUMEN:}

Este informe de investigación recoge los resultados de una exploración sobre la naturaleza de las afectaciones de un grupo armado, lo paramilitares, en una región colombiana; este ejercicio ha sido la antesala para planteamiento de una investigación que, recientemente aprobada, se propone ofrecer pautas para dar cuenta de aquellos impactos de la guerra que puedan ser definidos como "daño colectivo". En este orden de ideas, este artículo se propone exponer de la los resultados de esta aproximación preliminar que, a la manera de un estudio de caso, permiten establecer los alcances y limites analiticos de las aproximaciones de este carácter para dar cuenta de la dimensión de los daños colectivos a partir de la inspección de los tipos y naturaleza de las acciones paramilitares en el Chocó y Urabá antioqueños, durante el periodo 1998-2006.

\section{PALABRAS CLAVES:}

Paramilitares, Conflicto Armado, Daño Colectivo, Urabá, Chocó.

\section{ABSTRACT:}

The following article presents a deep discussion about the processes of psychosocial intervention with victims of political violence, in the light of their life stories in a context of research on the role of memory in the reconstruction of the social fabric. The category of the psychosocial emerged as a result of these life stories and discussion groups and allowed a critical look at the intervention processes that take place in Colombia, from the voice and the testimony of the participants. Finally, it also collects proposals from this same voice, that of the people, and forms of action involving a revision to the individualistic, pathological, vertical, technocratic, and bureaucratic models of the action, to propose comprehensive and systemic actions for the recovery of dignity and the subjective transformation from participation, dialogue of knowledge, playful and performative expression, and horizontal relationships, mutual support and construction of citizenship and subjectivity of rights.

\section{KEY WORDS AND EXPRESSIONS:}

Psychosocial intervention, psycho-social approach, victims of armed conflict, collective memory, mutual support.

\footnotetext{
${ }^{1}$ Docente investigador de la Facultad de Derecho de la Universidad San Buenaventura y Consultor del Observatorio Departamental del Desplazamiento Forzado. Convenio ACNUR/Gobernación de Antioquia. Correo Electrónico: nicolas.espinosa@usbmed.edu.co.
} 


\section{Introducción.}

La reparación colectiva de víctimas del conflicto armado es un tema de reciente acogida en el debate público que, originado desde funcionarios del estado y representantes de la sociedad civil, hace referencia a una de las variantes para la reparación que -junto a los derechos a la Verdad, la Justicia y las Garantías de no Repetición- se ha posicionado como condición imprescindible para la negociación con los grupos armados.

¿Cómo dimensionar las afectaciones colectivas? ¿Qué configura un daño colectivo? ¿Cómo rastrear tales afectaciones en un territorio? A partir de preguntas de este tipo, y con el propósito de ofrecer elementos de juicio para abordar este debate con este artículo daré cuenta de un ejercicio exploratorio que -a la manera de informe de investigación- me permita trazar los primeros esbozos de una metodología para definir, establecer y dimensionar los daños de índole colectivo derivados de la guerra en Colombia.

Este ejercicio lo he realizado, a la manera de un estudio de caso, tomando aspectos que dan cuenta de la dinámica del conflicto armado en una región en particular (la región Urabà/Chocó) y un grupo armado en especial: los paramilitares, en un periodo de tiempo que comprende el año 1998, momento en el que el proyecto nacional de las Autodefensas Unidas de Colombia agrupó organizaciones bajo la idea de una sola organización, y 2006, cuando se concretó la desmovilización de una facción paramilitar que hizo presencia en la región de Chocó y Urabá. Debo aclarar que así como las afectaciones colectivas no se limitan a las comunidades étnicas, afrocolombianas e indígenas (y así lo reconoce la reciente Ley de Víctimas), los responsables de tales afectaciones nos se reducen a los paramilitares, ni sus acciones al Chocó. Otros grupos armados, insurgentes y estatales, son responsables de este tipo de afectaciones, y otros tantos territorios escenario de sus actividades. Debo insistir, por tanto, que es este un estudio de caso que en aras de la delimitación lo he circunscrito a tal periodo, tal grupo y tal región.

Como rastreo preliminar que es, en este documento daré cuenta de cuatro elementos claves:

1. El marco normativo que establece y reconoce las afectaciones de índole colectivo y las posibilidades para la reparación de impactos de este tipo.

2. El marco histórico regional que, en términos de conflicto armado, permite caracterizar la expresión territorial de la guerra y la naturaleza, tanto de los grupos armados como de las afectaciones a que sus acciones dieron (y dan).

3. El tipo de lectura estadística (descriptiva) y cartográfica (temática) que es posible realizar (frente a las acciones paramilitares) a partir de fuentes secundarias reconocidas en el medio académico.

4. Algunas apreciaciones que pueden orientar el análisis en cuanto a las dimensiones de las afectaciones colectivas de los grupos paramilitares.

El escenario escogido comprende los municipios relacionados en la siguiente tabla (véase tabla 01) y siguiente mapa (véase mapa 01). 
Impactos del Paramilitarismo en la Región Urabá/Chocó 1998-2006. Claves para la Lectura de las Afectaciones Colectivas.

\begin{tabular}{|c|c|c|c|}
\hline \multirow{13}{*}{ 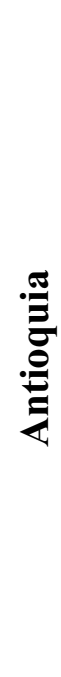 } & Municipios & \multirow{13}{*}{$\begin{array}{l}\stackrel{\circlearrowright}{8} \\
\stackrel{e}{0}\end{array}$} & Municipios \\
\hline & Arboletes & & Acandi \\
\hline & Cañasgordas & & Bojaya (bellavista) \\
\hline & Dabeiba & & Certegui \\
\hline & Frontino & & Condoto \\
\hline & Murindó & & Itsmina \\
\hline & Mutatá & & Jurado \\
\hline & Necoclí & & Medio san juan \\
\hline & Peque & & Riosucio \\
\hline & San Juan de Urabá & & Quibdo \\
\hline & Turbo & & Tado \\
\hline & Uramita & & Unguia \\
\hline & Vigía del Fuerte & & Unión Panamericana \\
\hline
\end{tabular}

\section{Municipios de influencia bloque Elmer Cárdenas}

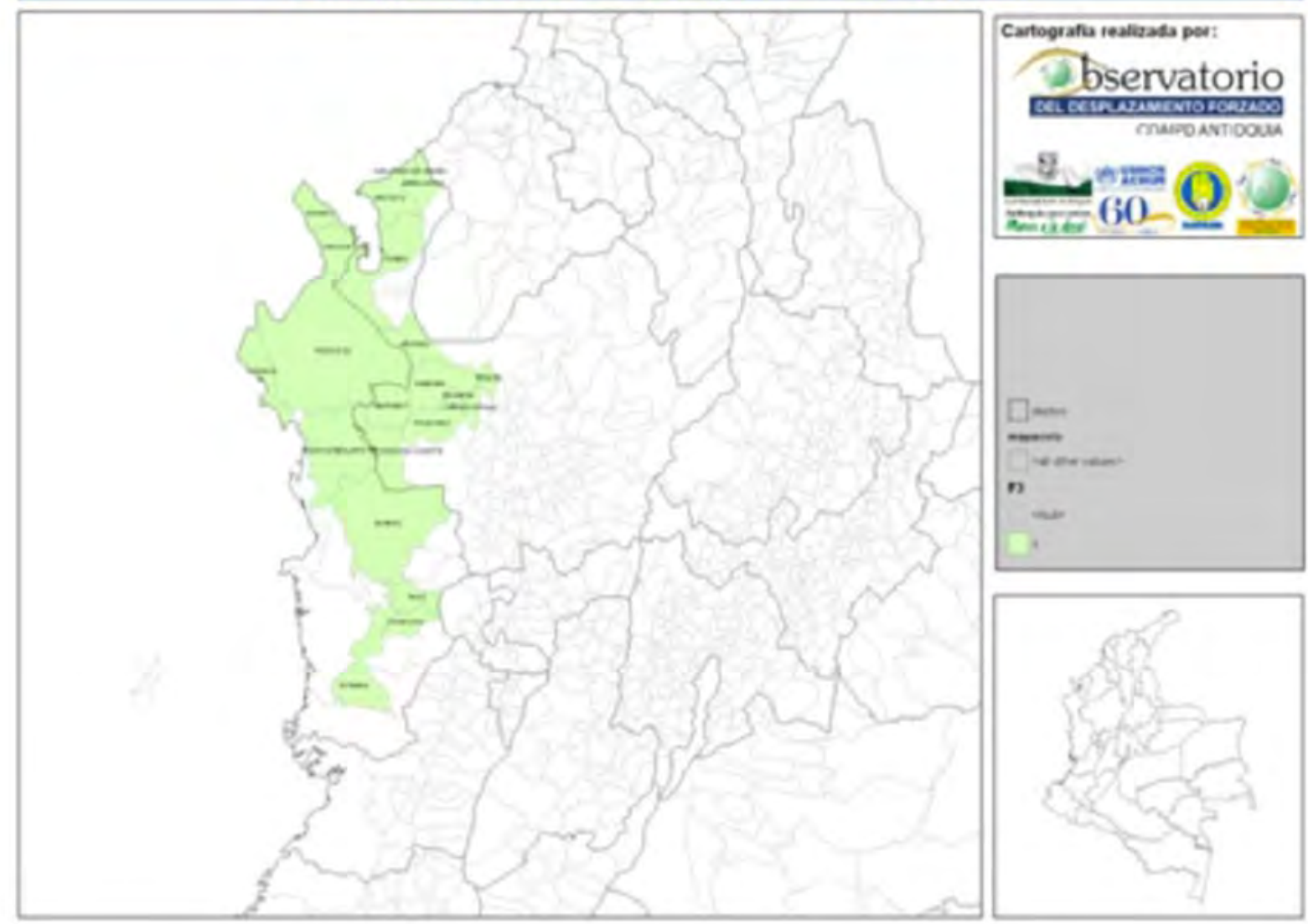

MAPA 01: Fuente: IGAC $^{3}$. 


\section{Metodologia:}

El análisis estadístico y cartográfico del comportamiento de las acciones paramilitares se sustenta en la sistematización de dos bases de datos sobre el conflicto armado:

- Base de Datos del Observatorio de DD.HH de la Vicepresidencia de la república la relación de Eventos del Conflicto que procesa el a partir de boletines diarios del DAS; número de desplazamientos que registra Acción Social y el número de Homicidios que contabiliza la Policía Nacional. Esta base cuenta con datos desde 1998 hasta el presente y fue procesada por el Observatorio Departamental de Desplazamiento Forzado de la Gobernación de Antioquia.

- Banco de Datos "Noche y Niebla" del CINEP. A partir de ella, en su versión análoga (1994-2001) y digital (2002-2006) depuramos y sistematizamos los registros de Violaciones a los Derechos Humanos e infracciones al DIH cuya responsabilidad recae en los paramilitares que hicieron presencia en la zona de estudio. Esta base fue procesada por el grupo Cultura, Violencia y Territorio de la Universidad de Antioquia.

El uso de dos bases distintas se deriva de las posibilidades que ofrecen: si desde la base de la Vicepresidencia es posible realizar análisis estadísticos a partir de una serie que recoge diversas variables, la base del CINEP permite llegar al trasfondo de los datos que registran eventos asociados al conflicto armado pues permite caracterizar la situación de conflictividad.

La región de estudio corresponde a la zona de operaciones del bloque Elmer Cárdenas de las Autodefensas Unidas de Colombia. Si bien ese fue el nombre de la estructura que entró en negociaciones con el estado colombiano, cabe aclarar que a lo largo del periodo analizado (1998-2006) los paramilitares que en la zona actuaron bajo órdenes o en asocio a los paramilitares de Carlos Castaño y John Fredy Rendón Herrera, alias "el alemán", se identificaron con distintos nombres como "Los Velengues", "El Grupo de la 70", "ACCU”, "Los Mochacabezas" etc.

El portal Verdad ${ }^{4}$ Abierta reseña la actividad histórica de los paramilitares al mando de Rendón, en donde se destaca que este bloque es responsable:

...de múltiples asesinatos, masacres, reclutamiento masivo de menores, desplazamiento de personas y atrocidades como descuartizamiento de personas. Muchas de estos crimenes, según han dicho los propios desmovilizados, se habrían cometido con anuencia de miembros de la fuerza pública, en particular de la Brigada XVII con sede en Carepa, Antioquia. De hecho en 2008 la Fiscalía vinculó al General en retiro Rito Alejo del Río a la investigación por la tortura, decapitación y asesinato de un campesino del Urabá Chocoano, cometido por los hombres al mando de "El Alemán", durante una operación que los desmovilizados han caracterizado como "conjunta" entre militares enviados por Del Río, y paramilitares del Elmer Cárdenas. "El Alemán" aceptó parcialmente también su responsabilidad en la masacre de Bojayá, Chocó, en mayo de 2002, cuando en medio de intensos combates entre paramilitares y guerrilleros de las Farc, estos últimos lanzaron un cilindro de gas que destruyó la iglesia donde se alberga la comunidad, y mató a 199 personas, la mayoría de los cuales eran niños.

292

AGO.USB Medellín-Colombia V. $12 \quad N^{\circ} 2$ PP. 214- 547 Julio-Diciembre 2012 ISSN: 1657-8031 
Los paramilitares, según se ha conocido, se apostaron y combatieron al lado de la iglesia. Las comunidades y los propios desmovilizados han relatado también que el río Atrato se convirtió en un inmenso cementerio donde fueron arrojados los cuerpos de quienes eran asesinados por este grupo paramilitar. La Comisión Intereclesial de Justicia y Paz señala al Bloque Elmer Cárdenas como responsable de haber cometido más de 110 crímenes de lesa humanidad, entre ellos 23 desplazamientos forzados ${ }^{5}$.

Como marco contextual para la lectura, tanto de situaciones como las que recién he citado y para las estadísticas con los que acompaño el análisis territorial, los apartados que siguen comprenden, en primer lugar una breve introducción a las definiciones normativas de daño y reparación colectiva; en segundo lugar el balance histórico del conflicto armado y papel que alli han jugado los paramilitares en la región Urabá/Chocó, para luego presentar -en tercer lugar- el análisis estadístico/comprensivo del comportamiento del conflicto armado durante el periodo analizado. Por último, en el cuarto apartado ofrezco algunas claves para comprender el carácter y la naturaleza de los paramilitares en la región y su papel en afectaciones de indole colectivo.

\section{Resultados - discusiones.}

Primera parte. Algunos elementos en la definición de daños y reparación colectiva: de la "ley de justicia y paz" a la "ley de víctimas".

En este apartado pretendo introducir elementos del marco normativo y de la perspectiva institucional frente a la reparación colectiva a impactos de esta naturaleza. Aspectos de este tipo son claves en la medida que permiten orientar, en términos institucionales, la búsqueda territorial de afectaciones y poblaciones sujetas y susceptibles a reparación colectiva. Es así que a la hora de dimensionar las afectaciones colectivas, un primer paso consistiria- en consecuencia- en el establecimiento de los marcos normativos y sociológicos que configuran las definiciones al respecto.

En declaraciones dadas por Eduardo Pizarro, primer presidente de la Comisión Nacional de reparación y Reconciliación, a la pregunta sobre "¿qué alcance tienen las declaraciones del señor Presidente en el sentido de que la reparación no va a ser completa?” se refirió al respecto:

"El problema de la reparación es que los costos de una reparación de carácter material se vuelven extremadamente complejos. ¿Cuánto vale un padre asesinado ?, ¿Cuánto vale un hijo asesinado ? Es decir, ¿uno puede cuantificar materialmente o en términos materiales el valor de un familiar asesinado ? Evidentemente jamás habrá una plena satisfacción. Nosotros vamos a intentar que haya una reparación simbólica y real. Por ejemplo, con un informe sobre los fenómenos de la violencia donde hay una condena moral, y las víctimas sientan que los criminales están siendo sancionados moralmente (CNRR 2005, SP).

Aunado a este reduccionismo, esta perspectiva ha permitido que los derechos a la reparación hayan sido confundidos, cuando no reducidos, a toda índole de servicios a que cualquier ciudadano tiene lugar. Al respecto aseguró Eduardo Pizarro: 
En segundo término, vamos a intentar hacer esfuerzos enormes para que a las víctimas a las que les han quitado sus bienes de forma ilegal, les sean devueltos. Y vamos a tratar, igualmente, que haya fórmulas de reparación colectiva para las víctimas. Por ejemplo, logrando que los hijos de las víctimas tengan un acceso real al sistema SISBEN, logrando que los hijos y los familiares de las víctimas tengan un acceso real en educación, logrando que las víctimas de la violencia tengan un acceso real a la formación técnica en el SENA, logrando que las víctimas de la violencia tengan un acceso real a otros beneficios del Estado (CNRR 2005, SP).

Pareciese que la reparación colectiva, entonces, se perfila desde los escenarios institucionales como una estrategia para agregar víctimas individuales, con el propósito de abaratar el costo -económico y político- de la reparación, al reducirla a una expresión simbólica cuyo carácter colectivo no va más allá de contemplar que esa reparación simbólica es, per sé, de carácter masivo.

El "acceso real" a estos servicios, valga aclarar, no está sujeto al reconocimiento de la condición de víctimas de cualquier ciudadano. Y la reparación de las afectaciones que las acciones de los grupos armados y la responsabilidad que allí le cabe al estado no se agota, ni mucho menos, en la provisión de servicios sociales y en la garantía de derechos ya adquiridos a la educación, la salud y la vivienda, entre otros.

Este debate frente a la reparación ganó relevancia en el marco de la negociación del gobierno Uribe con los grupos paramilitares, cuando la implementación de algunas expresiones de Justicia Transicional (forma de justicia que, en términos generales, plantea el transito de una sociedad de dictaduras a democracia, de guerra a paz ) la Ley 975 de 2005 (conocida como ley de "Justicia y Paz") tuvo como propósito conciliar los intereses de las partes involucradas en el proceso: las fuerzas en conflicto, la institucionalidad y las víctimas. Esto significó que, bajo este marco, la ley 975.

"regula bajo un procedimiento especial la investigación, la sanción penal y el otorgamiento de beneficios judiciales a los desmovilizados que resulten condenados por delitos atroces (otorgamiento de una pena alternativa, no mayor a 8 años) y por otro lado, busca incluir los elementos de la justicia transicional protegiendo los derechos de las víctimas." (Portal Verdad Abierta, SF; subrayado propio).

Tras la aprobación de la Ley, las demandas presentadas condujeron a la Corte Constitucional a realizar una serie de modificaciones en aras de fortalecer los principios de la Justicia Transicional, en donde según analistas consultados por el portal Verdad Abierta, no basta con reconocer formalmente en las normas la importancia de los principios de justicia transicional, la participación de las víctimas o garantizar el estricto cumplimiento de las condiciones previas y posteriores de la pena alternativa. Es necesario desarrollar un sistema institucional a partir del cual los operadores de las normas puedan orientar el proceso en concordancia con dichos principios (Verdad Abierta, SF).

Ahora bien, en tanto a la serie de afectaciones colectivas a que ha dado lugar el conflicto armado, la recién aprobada Ley de Víctimas (Ley 1448 de 2011) establece en principio un parámetro que delimita el carácter colectivo de las afectaciones al establecer, en su artículo 2 , que.. Las medidas de atención, asistencia y reparación para los pueblos indígenas y

294

AGO.USB Medellín-Colombia $\quad$ V. $12 \quad N^{\circ} 2$ PP. 214- 547 Julio-Diciembre 2012 ISSN: 1657-8031 
comunidades afrocolombianas, harán parte de normas específicas para cada uno de estos grupos étnicos, las cuales serán consultadas previamente a fin de respetar sus usos y costumbres, así como sus derechos colectivos, de conformidad con lo establecido en el artículo 205 de la presente ley. (Min Interior y Justicia 2011).

Más adelante, en el Capítulo XI, "Otras medidas de reparación", se amplía el espectro del universo de víctimas colectivas por medio del reconocimiento tanto derechos de carácter colectivo, como el ser sujetos de reparación en esta vía a través de un futuro "Plan Nacional de Atención y Reparación Integral a las Víctimas". A partir de este plan se deberá (dice la ley 1448 de 2011 en su artículo 151): implementar un Programa de Reparación Colectiva que tenga en cuenta cualquiera de los siguientes eventos: a) El daño ocasionado por la violación de los derechos colectivos; b) La violación grave y manifiesta de los derechos individuales de los miembros de los colectivos; c) El impacto colectivo de la violación de derechos individuales. (Min Interior y Justicia 2011).

Son sujetos de reparación colectiva, por ende (y según la ley 1448 de 2011 en el artículo 152): grupos y organizaciones sociales y politicos; comunidades determinadas a partir de un reconocimiento jurídico, político o social que se haga del colectivo, o en razón de la cultura, la zona o el territorio en el que habitan, o un propósito común (Min Interior y Justicia 2011).

En la medida que en la zona analizada, donde ejercieron influencia paramilitares que se identificaron como pertenecientes al bloque Elmer Cárdenas, para dar cuenta de las condiciones históricas de esta subregión el siguiente apartado daré cuenta de los antecedentes históricos mas relevantes, en términos del conflicto armado, del Urabá. Puesto que sobre el chocó los registros históricos y sociopolíticos son mínimos, en esta versión preliminar me he centrado en el Urabá antioqueño.

Segunda Parte. Antecedentes históricos en la configuración del conflicto armado en el Urabá antioqueño.

La situación del Urabá antioqueño ha trascendido las fronteras departamentales para convertirse en una realidad paradigmática en términos de lo que significa la agudización del conflicto y la degradación de la lucha insurgente y contrainsurgente en Colombia. La historia del conflicto armado en la subregión no se ha terminado de escribir quizá porque lejos de ser una subregión pacificada, el que el paramilitarismo consolidase su presencia en los cascos urbanos y las zonas llanas del Urabá y que la fuerza pública ampliara su radio de acción en las zonas rurales, cerrándoles con esto espacio político y militar a las Farc, los hechos de violencia política muestran que la situación está lejos de "calmarse" y que las Farc no han desaparecido allí. En este apartado recojo algunas consideraciones regionales de mi autoría que realizara para una investigación en el Instituto de Estudios Regionales ${ }^{6}$.

El control paramilitar, según se desprende de las denuncias recogidas por el banco de datos Noche y Niebla de CINEP, se hace extensivo a los mas variados ordenes sociales y se reproduce en la cotidianidad de la región bananera de una forma tal que es difícil ocultar el carácter funcional que su presencia y jurisdicción significan para la Fuerza Pública. Así mismo, la agresividad con que las Farc se han planteado la "retoma" del Urabá, incluso en 
tiempos de lo que A. Rangel ha llamado "repliegue estratégico" (2005), es un proceso de vieja data que se remonta a finales de los 90 cuando los bloqueos en el Cañón de la Llorona se hicieron extensivos e incluso desafiantes: retenes a la carretera que comunica Medellín con Urabá durante varios días ${ }^{7}$. Subsiguientes incursiones paramilitares lograron diezmar apoyos locales a la ofensiva de las Farc en los municipios aledaños al eje bananero, pero aún así las cifras sobre incursiones de las Farc en la región, aunque respetan la tendencia general de Antioquia y del país que apuntan a una baja, se mantiene constantes ${ }^{8}$.

Esta historia, efectivamente tiene su historia. Y como son varios los sucesos y condiciones preexistentes que han contribuido a configurar la situación del Urabá este texto recoge una serie de contribuciones académicas y elementos para el análisis que permiten acercarse a una dimensión más amplia a partir de la serie de mapas producto de esta investigación.

Subregión y conflicto: hitos del desarrollo histórico.

La clave para la comprensión de la situación del Urabá pasa por comprender los distintos quiebres históricos que en la región han sucedido. Quiebres que estuvieron marcados, hasta bien entrada la década del noventa, por la búsqueda de un amplio control sobre la política que en Urabá ha estado fundamentado, según la investigadora L. Villegas, "en dos manifestaciones: la participación electoral y la guerra de guerrillas, ambas vinculadas a los conflictos laborales, de tenencia de la tierra y la política partidista" (Villegas 1995:1).

La lucha por la politica en la región se ha comprendido a partir de dos etapas que, por sus condiciones, gestaron conflictos a partir de condiciones sociales que con el tiempo se fueron complejizando. La primera se extiende hasta 1979, tiempo en el que la colonización del Urabá atrajo población, lideres sociales, dirigentes políticos, agentes económicos. Algo que caracterizó esta larga temporada de colonización y poblamiento fue la configuración de los conflictos sociales como independientes los unos de los otros. "La segunda etapa se inicia en la década de 1980 y en ella los conflictos se articulan, de tal manera que el conjunto regional adquiere nueva dinámica y significación" "(García 1998:85).

La guerrilla apareció en el Urabá a finales de los 60 cuando las Farc expandieron sus frentes. Urabá fue terreno propició por cuanto allí llegaron colonos cercanos al Partido Comunista quienes habían avanzado en la organización política del campesinado. A principios de los 70, luego de la división internacional del bloque comunista, el EPL surge como la respuesta y apuesta armada del sector maoísta escindido del Partido Comunista. Bernardo Gutiérrez, comandante del V Frente deserta junto con varios de sus hombres y armas y se integra al EPL, arrastrando consigo las redes y circuitos propios de la clandestinidad que permitirian al EPL ampliar su margen de acción de Córdoba al Urabá. En los años 80, tras un replanteamiento político, el EPL se incrusta en el corazón del eje económico, social, y político con su inserción en los sindicatos y con las invasiones de tierra en zona rural y en los núcleos urbanos. Con lo anterior el conflicto guerrillero acaba condicionando la dinámica del conjunto de los conflictos sociales y el territorio se divide grosso modo entre norte-EPL- y el sur -Farc-. El eje bananero se convierte en eje de la disputa interguerrillera. (García 1998b:81). 
En la primera etapa señalada anteriormente, la confrontación entre guerrilla y ejército se dio en un plano estrictamente militar y en un terreno que se extendió, e involucró, regiones aledañas al eje bananero, al que García (1996) en sus estudios llamó "la periferia regional". A partir de la década del ochenta cambian los términos de la relación y del significado del conflicto entre Estado y guerrillas. El centro de la acción pasa a dirimirse en el eje bananero y sobrepasa lo puramente militar, pues el poder político es competido también en el terreno de la movilización de masas y de la política de paz.

Las tensas relaciones laborales que se vivieron en el Urabá hasta la consolidación del movimiento sindical, quienes lograron minimas condiciones de dignidad labora, fue un proceso que estuvo atravesado por la influencia guerrillera, en especial la del EPL cuando a principios de los 80 decide "bajar del monte" y realizar "trabajo de masas". Esa redefinición del trabajo del EPL, dice García "obliga a os demás actores regionales a redefinirse igualmente: la organización de un sindicalismo beligerante y masivo bajo control guerrillero; el replanteamiento de los términos en que las FARC hacen presencia en la región; la organización de un patronato hasta entonces disperso y desentendido de lo que aconteciera más allá del cerco de su empresa; y un nuevo tipo de intervención y de papel del Estado nacional en la región..." (García 1996:122).

El enfrentamiento entre sindicatos, que era una tradición en la "cultura sindical" del Urabá, se acrecienta con la estrategia guerrillera que lidera el EPL con su trabajo político de masas, pues al trabajo amplio y legal se sobreponen los métodos propios de la confrontación militar. Es decir: la persecución sindical de parte de la elite empresarial (apoyados por el estado) se recrudece y se "legitima" gracias a las acusaciones y señalamientos que los ligan con las estructuras armadas. De igual forma los sindicatos orientados por las FARC y por el EPL dirimen las connaturales luchas de poder entre sindicatos, no por vía democráticas sino mediante asesinatos selectivos. Este panorama se agudiza al mediar la década del 80. "Lo que observamos en Urabá en 1985, es una reedición de procesos anteriores, pero con los nuevos actores contestatarios del momento; las guerrillas". (García 1996:132).

Coincide con las intenciones del EPL el proceso de paz con la administración Betancourt y su trabajo de masas se extiende y diversifica. Actuando más como fuerza social el EPL hace las veces de un partido político legal que de forma abierta logra ganar respaldo entre sectores bananeros. Pero luego, cuando fracasa el proceso de paz de Betancourt vendrá una agudización en la "guerra sindical" que libaron el EPL y las FARC.

A partir de este momento se desencadenará un fuego cruzado entre varios grupos armados ilegales de diversas orientaciones políticas extremas, de izquierda (guerrillas) y de derecha. Pero la complejidad del asunto reside en que afecta principalmente a movimientos políticos legales de todas las tendencias en la zona, a los sindicatos que han visto la coacción armada y la violencia de diversos rostros intervenir en sus asuntos, a los grupos empresariales que padecen la violencia insurreccional y delincuencial diariamente, a los campesinos en las zonas de conflicto armado en medio de varios fuegos y en general a la sociedad civil que sufre diariamente estas violencias cruzadas. (Botero 1990:222). 
La consecuencia de este proceso es descrita por C. García como una reconfiguración del conflicto subregional a partir de la negociación con el EPL, puesto que "al no contar el estado con una estrategia de control del territorio abandonado por el EPL, son los grupos armados -guerrilleros y paramilitares- quienes se dan a esa tarea. Cambia así sustantivamente la territorialidad de los actores en armas y la calidad y dinámica del conflicto: a) Se consolida la estrategia paramilitar para "recuperar" militar, política y económicamente el territorio a costa de una guerra que, desde los dos flancos que la agencian, rompe todos los cánones del DIH. B) los reinsertados se convierten en objetivo militar de ambos mandos armados" (García 1998:89) situación que condujo a la cooptación de parte de organismos de seguridad el estado y la creación de comandos populares. Es decir, la paz fue a medias y el proceso no culminó en la reversión del proceso de escalonamiento que se pretendió.

¿Qué sucedió desde entonces? La conformación de la Coordinadora Nacional Guerrillera contribuyó al cese de la "guerra sindical" mientas esta alianza guerrillera perduró; alianza que se materializó, incluso, en la unidad sindical entre los grupos obreros influenciados, o bien por las Farc o bien por el Epl, en el año de 1989.

Pero el panorama político y la influencia guerrillera en el movimiento obrero dificulta enormemente la actividad sindical y la actividad económica en la región, porque esta situación ha llevado a una creciente "militarización de la política" y ha desembocado en una violencia generalizada y difusa, desventajosa para todos los grupos que viven en la región (Botero 1990:222).

Irrupción paramilitar en el Urabá.

Entre los años 1981 y 1995 la situación de Urabá, según Villegas, contempla las siguientes condiciones: expansión y crisis de la agroindustria, orientación de la colonización hacia el Chocó y la serranía de Abibe, invasiones a tierras urbanas y suburbanas y la generalización de los conflictos que desde antes existían y que anteriormente se han señalado (Villegas 1995:3).

La irrupción paramilitar marca esta época y su ejercicio de poder y control social marcan la pauta en la dinámica regional. Con el apoyo de ganaderos e industriales renuentes al boleteo guerrillero el proyecto paramilitar se origina desde las áreas rurales y desde allí irradian su acción a las cabeceras municipales.

Ellos mantiene un control y una vigilancia permanente de los espacios, patrullan las carreteras y controlan las vías de acceso. Sus principales centros de operaciones estaban en San Pedro de Urabá, Pueblo Bello, Necoclí, parte e la serranía de Abibe, o sea, en aquellos territorios donde tuvieron asiento las guerrillas liberales de los años cincuenta" (Villegas 1995: 17).

El papel de la guerrilla en la consolidación del paramilitarismo no entra en saco roto. Su responsabilidad es tema obligado para entender los alcances y fuerza que alcanzan a tener estos grupos. Responsabilidad que se dirige a dos escenarios y distintas responsabilidades. Por un lado los excesos de las Farc, por otro una política de paz fraccionada que desmovilizó 
una parte EPL pero no llego a acuerdos con las FARC ni fue capaz de cesar la vieja hostilidad de ambas guerrillas, una de ellas ex-guerrilla y desde entonces partido político. El conflicto, nuevamente, se traslado de la confrontación entre aparatos armados a la confrontación entre un aparato armado (Farc) y una expresión civil (Esperanza Paz y libertad, partido político del EPL) contraria a sus objetivos. De igual forma entran a jugar los paramilitares que como aparato armado extendieron la practica antes descrita en contra de la unión Patriótica. Situación que se torna más perversa aún cuando desmovilizados del EPL se integran al paramilitarismo.

La situación subregional, descrita por la investigadora antes citada, puede describirse así: al mediar la década del Noventa y tras un nuevo fracaso en la politica de paz "las acciones de la guerrilla -especialmente del frente Bernardo Franco, disidencia del EPL- y los incumplimientos de los pactos de paz por parte de los desmovilizados llevó a que en los últimos años se diera con mayor fuerza la presencia de los grupos paramilitares en el norte, con el objeto de recuperar sus propiedades, recuperar para si ese territorio y mantener el poder. En estas condiciones surgen dos vertientes entro de los grupos paramilitares, unos orientados a recuperar sus propiedades y defender sus vidas -un proyecto de tipo económico. Y otros, a defender el territorio del comunismo, un proyecto mas de tipo político. Este último esta orientado desde Valencia (Córdoba) por Fidel Castaño y sus hermanos, quienes llegaron a la zona desde 1987, procedentes del Magdalena medio donde se les conoció por su liderazgo en los grupos paramilitares de esa región." (Villegas 1995:18).

El paramilitarismo es, desde entonces, el actor fundamental en la configuración regional desplazando para este efecto la confrontación entre las que fueran las guerrillas hegemónicas en la región. Pero su papel predominante en el control territorial no debe dejar perder de vista la presencia permanente de las Farc en las zonas rurales de los municipios cercanos al nudo de paramillo y Chocó. Según consta en el seguimiento que hace el banco de datos Noche y Niebla de CINEP las Farc no han desaparecido de la región, haciendo que la llamada "pacificación" del Urabá, si bien fue mostrada como un hecho concreto y exitoso, quizá deba adscribirse geográficamente a los cascos Urbanos y determinadas zonas de influencia.

Pacificación que encuentra un ingrediente importante para tener en cuenta el panorama confuso de este proceso, puesto que en buena medida se fundamentó en la cooptación de desertores guerrilleros en las filas paramilitares. "En el disponer de valiosa información sobre el accionar interno, las rutinas y las bases sociales de la guerrilla puede estar, quizás, la clave del éxito de la tan publicitada "pacificación de Urabá" para finales de 1996" (Uribe 2000i: 40).

Época que coincide con la declaración de Urabá como "Zona Especial de Orden Público". "Los cuatro municipios del Eje Bananero son puestos bajo control militar decretado por el gobernador Alvaro Uribe Vélez. Esta estrategia está encaminada a controlar el transporte en la zona, mediante instalaciones de retenes móviles y fijos, pues se parte de la siguiente premisa: "el transporte es un punto neurálgico del orden público en Urabá, de las masacres y de la movilización de drogas y armas". (Uribe 2005i: 43) Estrategia que solo funcionó para exacerbar el conflicto, pues ante la lucha se definió como centro de la confrontación, el "todo regional": Apartadó y Turbo, en un marco de enfrentamiento entre pacificación y reconquista. (Uribe 2005i:70). 
Tercera parte. Comportamiento de las Acciones armadas en los municipios de presencia del bloque Elmer Cárdenas.

En este apartado estableceré las principales características y extensión territorial de los acciones paramilitares a partir de datos estadísticos. Las graficas y mapas establecerán las acciones paramilitares desarrolladas en la región del Urabá según el departamento de ocurrencia (Antioquia o Chocó).

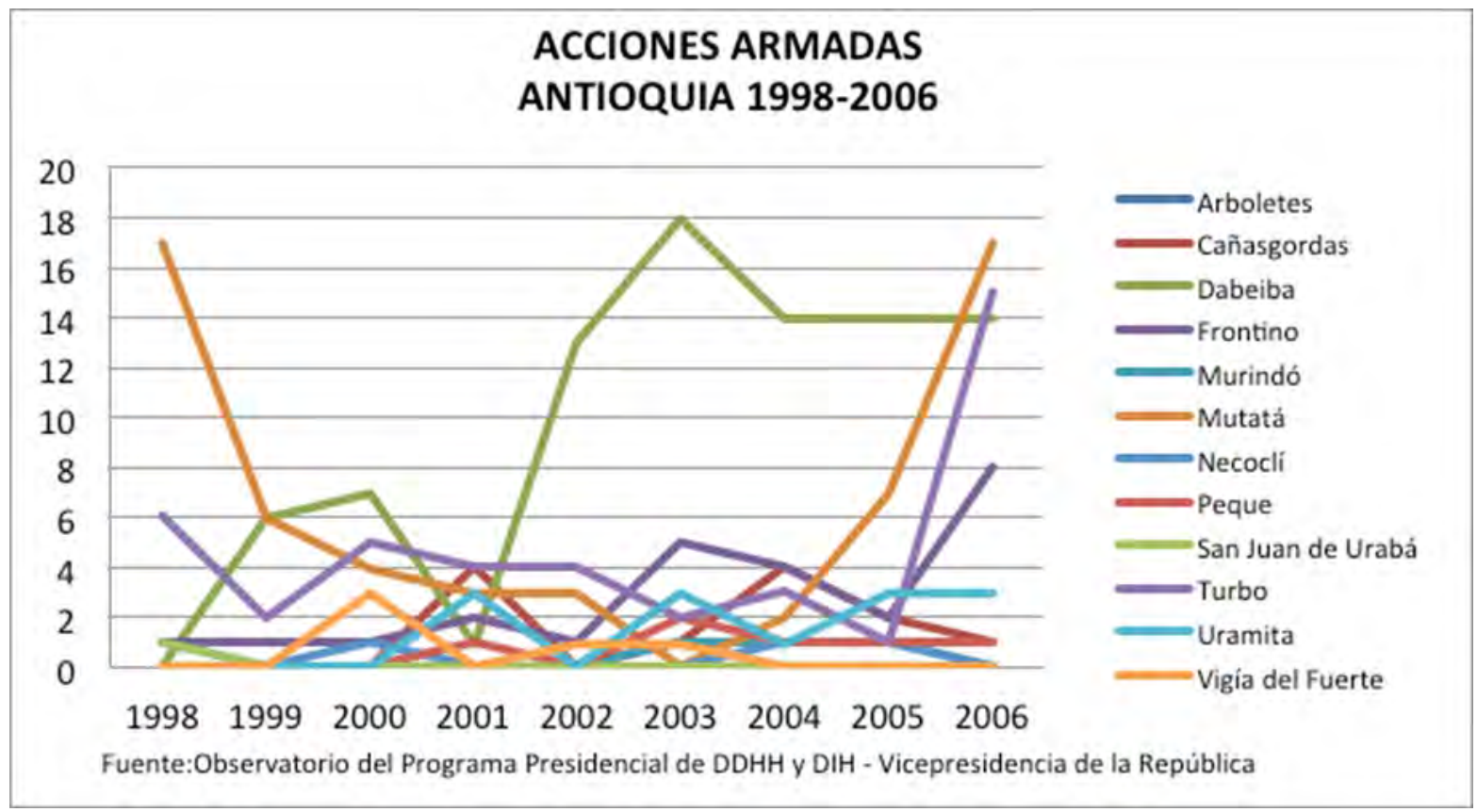

Gráfica 01 Fuente: observatorio de DD.HH. de la vicepresidencia

La base de datos del Observatorio de DD.HH de la Vicepresidencia permite graficar el comportamiento de las acciones armadas en los municipios de Antioquia (gráfica 01) y Chocó (gráfica 02) donde hiciera presencia el grupo paramilitar "Elmer Cárdenas". Las graficas construidas dan cuenta del comportamiento de la violencia armada en cada municipio y la forma en que algunos de ellos sobresalen sobre los demás por la intensidad y periodicidad de sus acciones. 


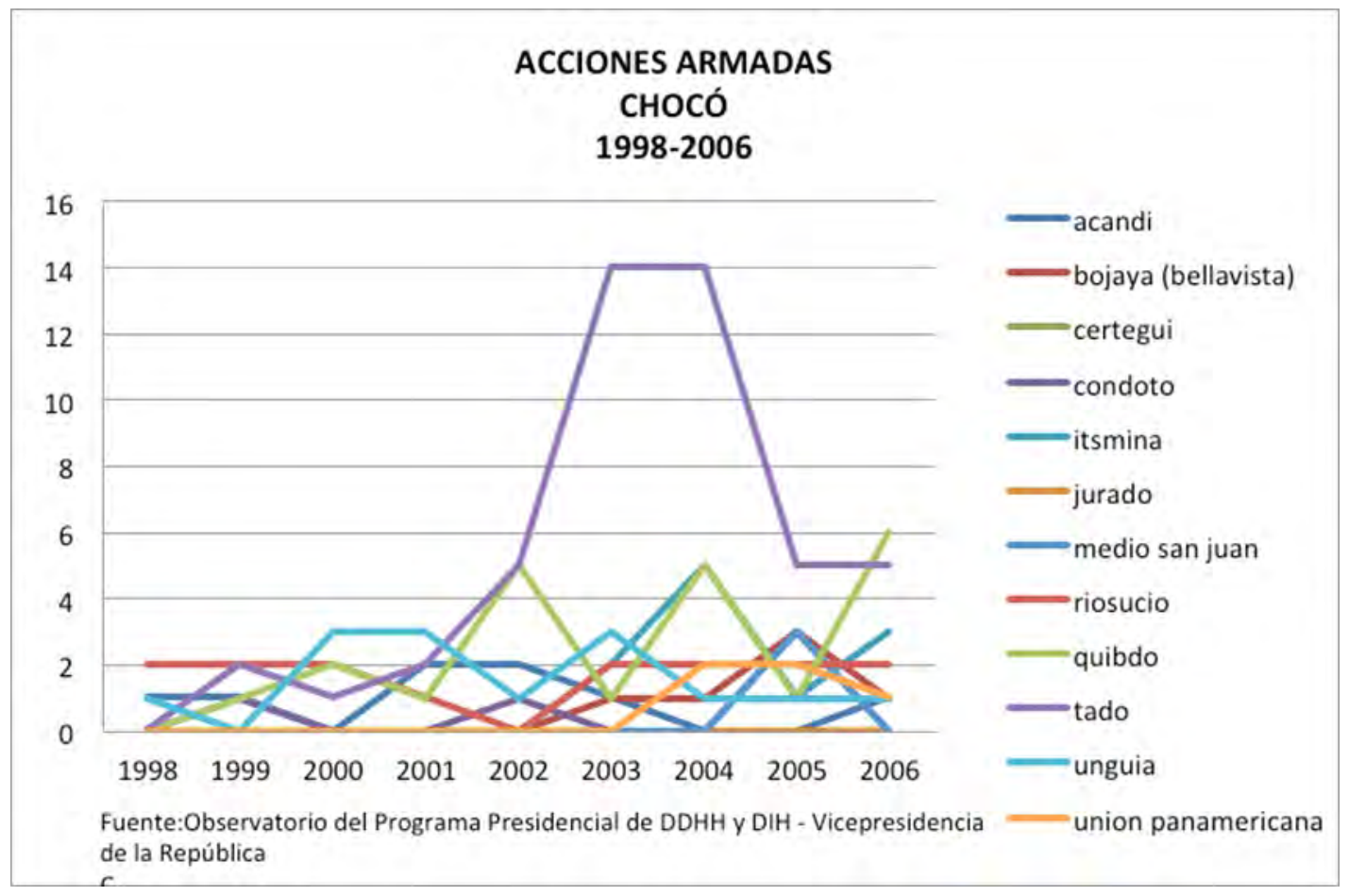

Gráfica 02 Fuente: Observatorio de DD.HH. de la Vicepresidencia.

Se destacan como los municipios con mayor número de acciones armadas, por ejemplo, Dabeiba, Mutatá, Frontino y Turbo en Antioquia; Condoto y Quibdó, en Chocó.

Para el cálculo de estas acciones armadas hemos agregado los eventos registrados como obra de grupos armados ilegales (Farc, ELN, Paramilitares) y las acciones por iniciativa de la fuerza pública. El total de acciones observan, a lo largo de la región de estudio, el comportamiento expresado en la Grafica 03

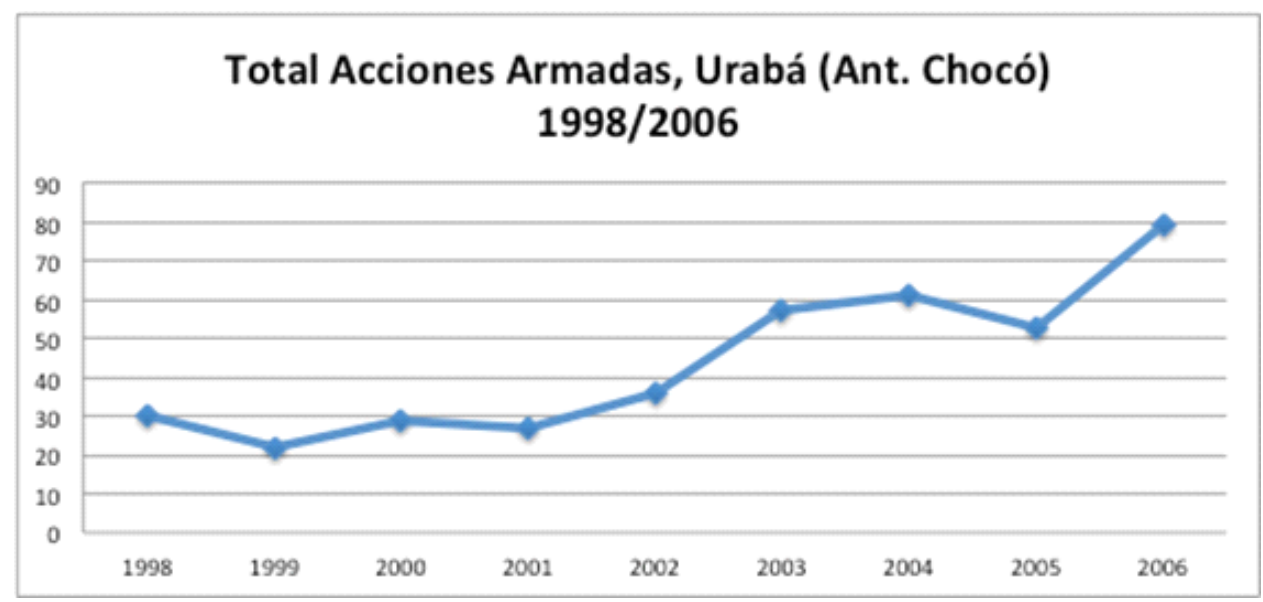

Gráfica 03 Fuente: Observatorio de DD.HH. de la Vicepresidencia. 
Este total de acciones armadas en la región se encuentra desagregado como se observa en la siguiente gráfica:

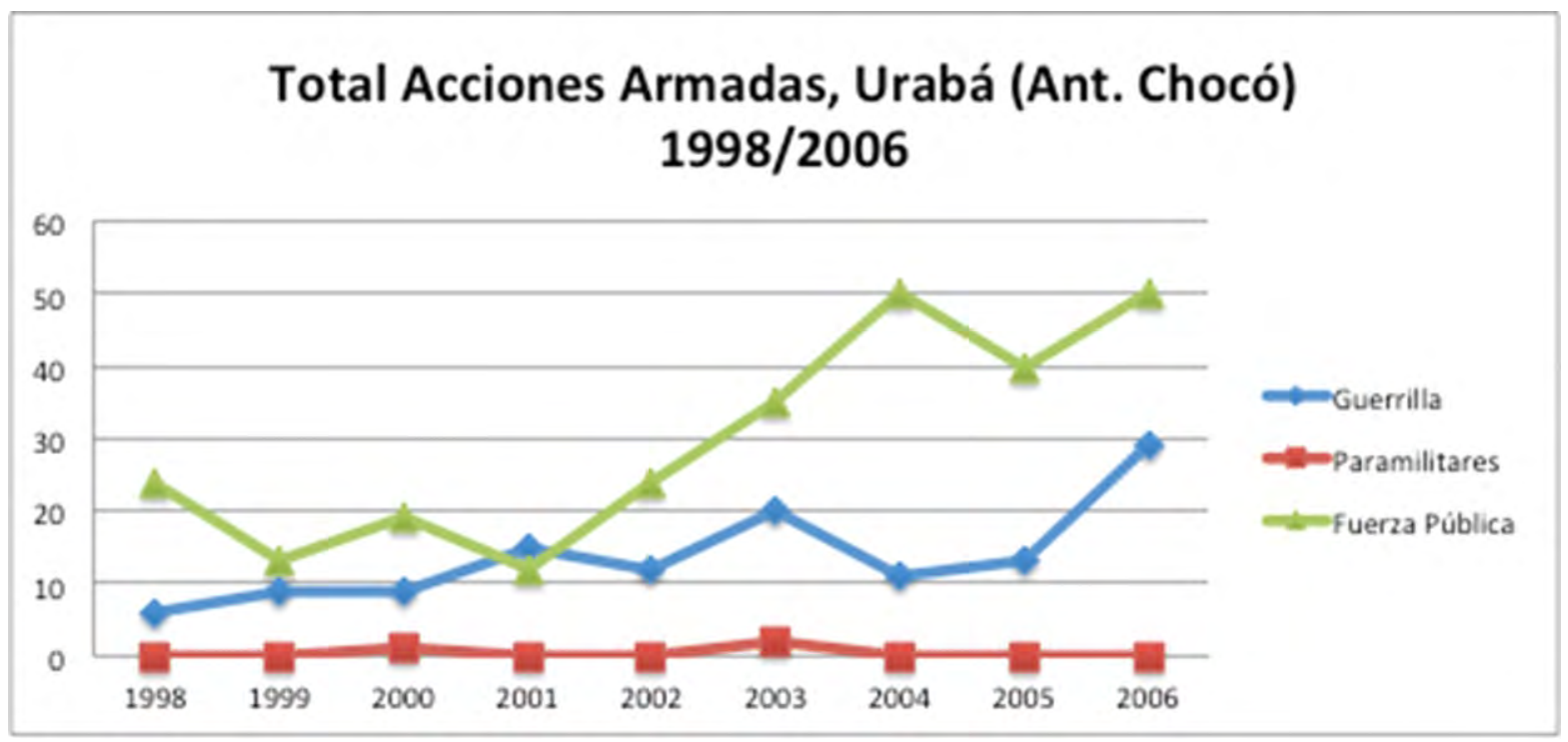

Gráfica 03. Fuente: Observatorio de DD.HH. de la Vicepresidencia.

Esta relación de acciones por grupo da cuenta de un mínimo registro de acciones paramilitares en la región. Las acciones de la fuerza pública aquí señaladas tienen un comportamiento -según grupo combatido- claramente diferenciado:

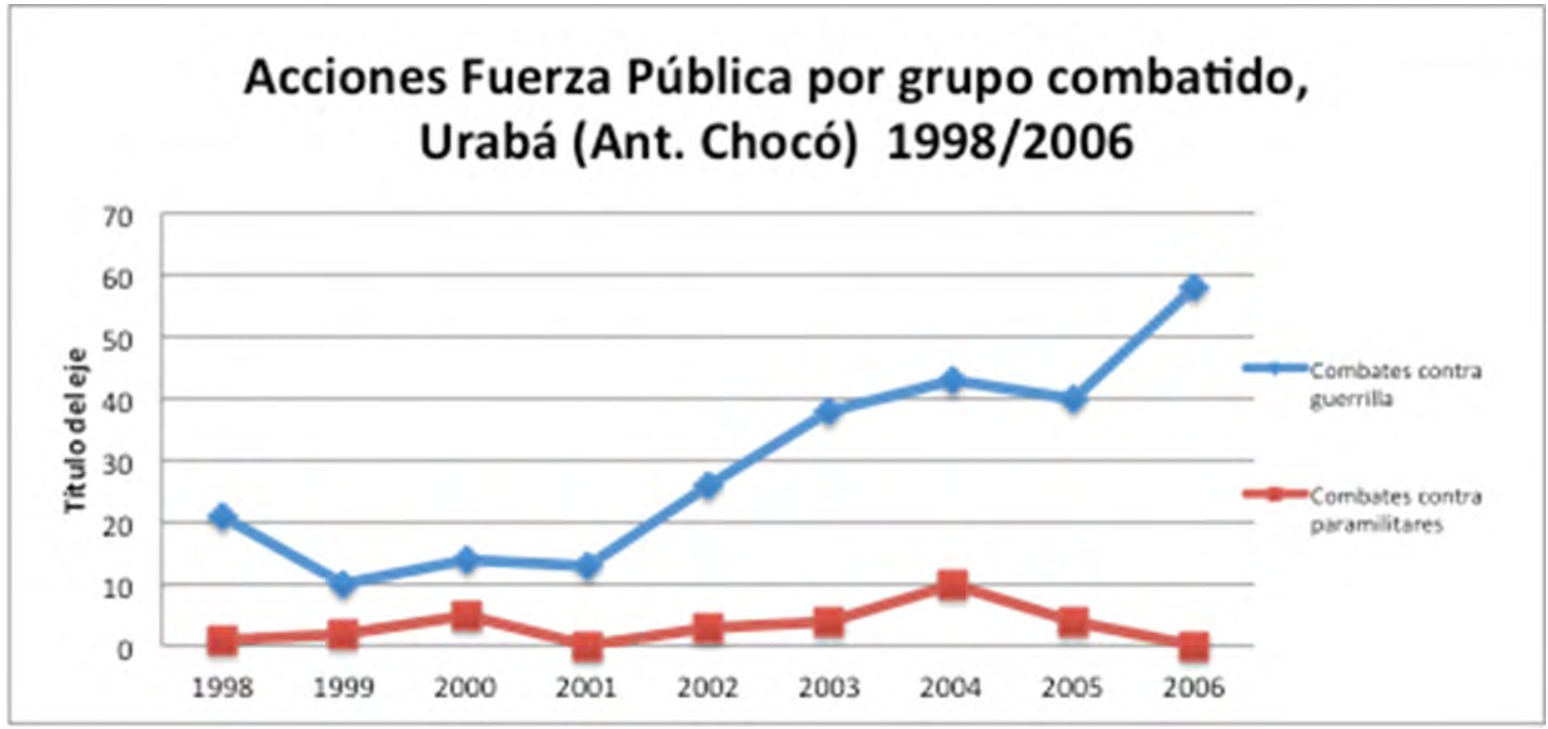

Gráfica 04. Fuente: Observatorio de DD.HH. de la Vicepresidencia.

302

AGo.USB Medellín-Colombia V. $12 \quad N^{\circ} 2 \quad$ PP. 214- 547 Julio-Diciembre 2012 ISSN: 1657-8031 
Esa distancia entre la intensidad de grupo combatido es lógica en la medida que la presencia de los paramilitares, según esta fuente y según el total de acciones paramilitares registradas, fue muy baja durante el periodo analizado.

Desde otra perspectiva analítica, el Banco de Datos "Noche y Niebla" del CINEP -otra de las fuentes de información utilizadas por el Observatorio de Desplazamiento Forzado- da cuenta de la situación en otra magnitud.

Según Noche y Niebla durante el periodo 1994/2006 fueron registrados 398 acciones paramilitares, 161 en Chocó, 237 en Antioquia. Valiéndonos del periodo 1998-2006 (el mismo del cual dispone datos el Observatorio de la Vicepresidencia), fueron 204 las acciones paramilitares registradas durante este tiempo. El total de acciones mostró el siguiente comportamiento:

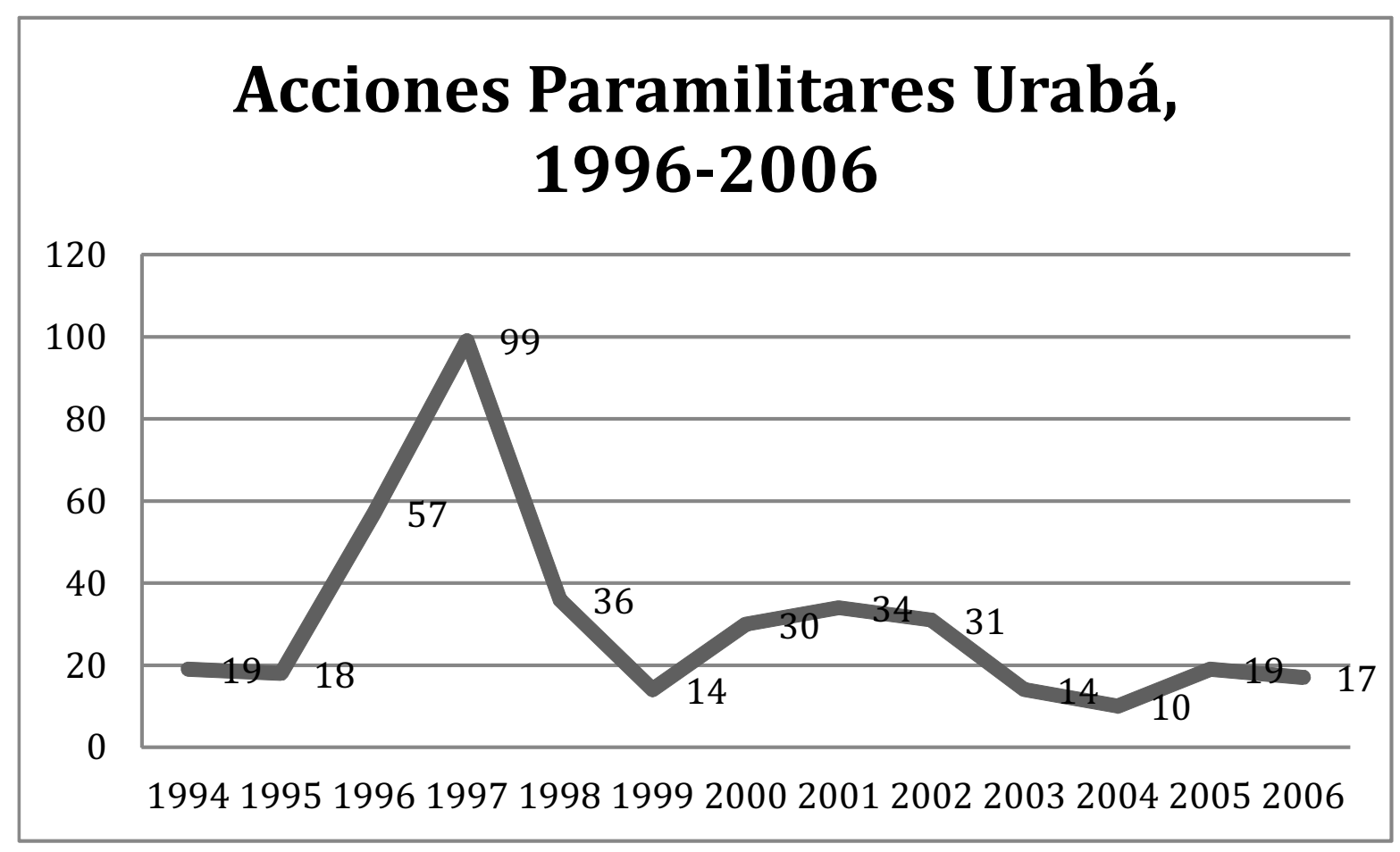

Gráfica 05. Fuente: Banco de Datos Noche y Niebla, CINEP. 
La siguiente es la relación de estas acciones en los mpios. de la región analizada.

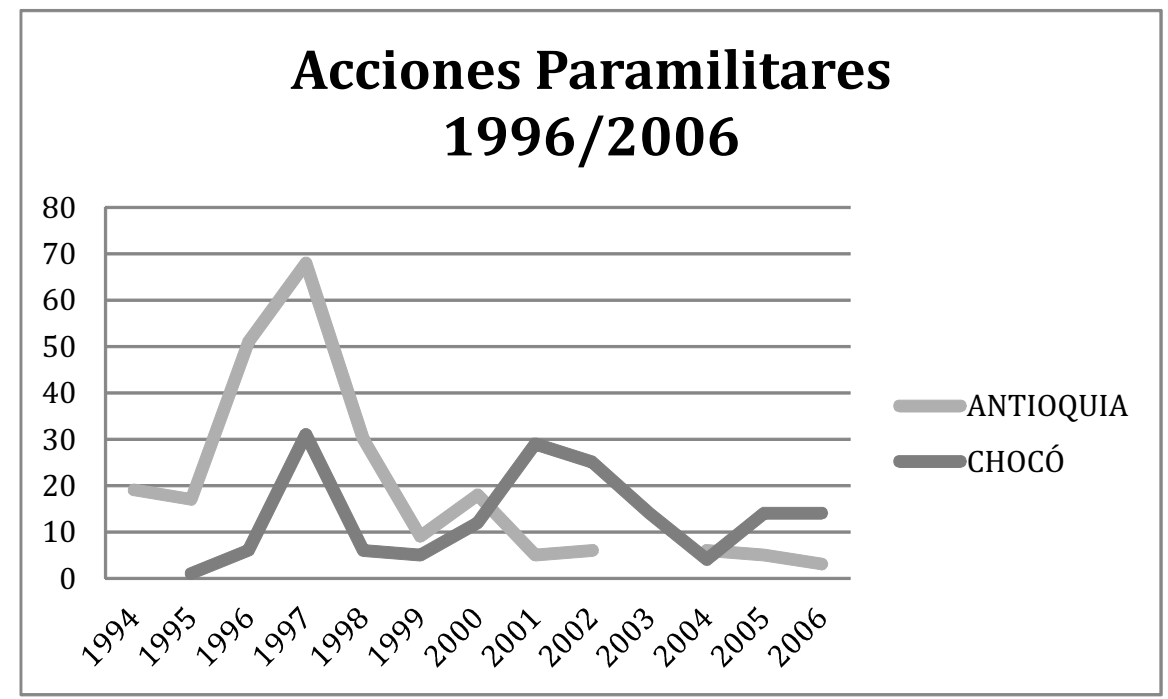

Gráfica 05. Fuente: Banco de Datos Noche y Niebla, CINEP.

La siguiente tabla da cuenta del total de acciones paramilitares por departamento y por totales cada año (para ver la desagregación municipal, véase anexo):

\begin{tabular}{lccc}
\hline $\begin{array}{l}\text { Contar de } \\
\text { Municipio }\end{array}$ & Etiquetas de columna & & \\
\hline AÑOS & ANTIOQUIA & CHOCÓ & $\begin{array}{c}\text { Total } \\
\text { general }\end{array}$ \\
\hline 1994 & 19 & & 19 \\
1995 & 17 & 1 & 18 \\
1996 & 51 & 6 & 57 \\
1997 & 68 & 31 & 99 \\
1998 & 30 & 6 & 36 \\
1999 & 9 & 5 & 14 \\
2000 & 18 & 12 & 30 \\
2001 & 5 & 29 & 34 \\
2002 & 6 & 25 & 31 \\
2003 & & 14 & 14 \\
2004 & 6 & 4 & 10 \\
2005 & 5 & 14 & 19 \\
2006 & 3 & 14 & 17 \\
Total general & $\mathbf{2 3 7}$ & $\mathbf{1 6 1}$ & $\mathbf{3 9 8}$ \\
\hline
\end{tabular}

Tabla 02. Fuente: Banco de Datos Noche y Niebla, CINEP.

304 
Cada acción paramilitar implico la ocurrencia de uno o mas eventos definidos en el marco metodológico de Noche y Niebla como violaciones a los DD.HH, infracciones al DIH o acciones bélicas (es decir, aquellas que se ajustan a las normas que rigen a los conflictos armados; véase Noche y Niebla 2008). En la medida que Noche y Niebla tipifica como violación a los DD.HH cuando esta es producto de "...agentes del Estado o por particulares que actúan con el apoyo, tolerancia o aquiescencia de las autoridades del Estado". La desagregación de las violaciones a los DD.HH cuyas denuncias hacen responsable a los paramilitares nos arroja que durante el periodo analizado, del total de 398 acciones paramilitares implicaron la ocurrencia de no menos de 786 modalidades de violaciones a los DD.HH e infracciones al DIH. De este total de violaciones, tan solo se registraron nueve acciones bélicas que se apartaron de las normas que regulan la guerra.

La siguiente tabla da cuenta de las principales características de estas modalidades y su frecuencia, destacando -en algunas de ellas-aspectos de las denuncias que permiten comprender la naturaleza de las acciones (i.e. degollamientos, decapitaciones, etc) En la mediad que algunas de estas generan un fuerte impacto en las comunidades: 


\begin{tabular}{|c|c|}
\hline $\begin{array}{l}\text { Frecuencia de Violaciones DD.HH, Infracciones y Accio } \\
\text { Bélicas }\end{array}$ & \\
\hline $\begin{array}{l}\text { Tipo de acción (Violación DD.HH; Infracción DIH; Accion } \\
\text { Armada) }\end{array}$ & Total \\
\hline Amenaza & 1 \\
\hline Atentado & 1 \\
\hline Bienes despojados & 1 \\
\hline Decuartizamiento & 1 \\
\hline Degollados & 1 \\
\hline Destrucción Bienes Civiles & 1 \\
\hline Detención & 1 \\
\hline Enfrentamiento & 1 \\
\hline Incedio intencionado & 1 \\
\hline Infracción contra misión médica & 1 \\
\hline Secuestro & 1 \\
\hline Violación & 1 \\
\hline Bloqueo de vías & 2 \\
\hline Confinamiento como represalia & 2 \\
\hline Muerto en acciones bélicas & 2 \\
\hline Abuso de Autoridad & 3 \\
\hline Control de bienes indispensables para la supervivencia & 6 \\
\hline Heridos & 8 \\
\hline Amenaza & 9 \\
\hline Combate & 9 \\
\hline Decapitación & 10 \\
\hline incendio Intencionado & 10 \\
\hline Detención arbitraria & 14 \\
\hline Retén & 18 \\
\hline Despojo de bienes & 26 \\
\hline Tortura & 35 \\
\hline Connivencia & 39 \\
\hline Incursión & 39 \\
\hline Masacre & 44 \\
\hline Colectivo desplazado & 45 \\
\hline Desaparición & 70 \\
\hline Colectivo Amenazado & 104 \\
\hline Ejecución extrajudicial & 279 \\
\hline Total general & 786 \\
\hline
\end{tabular}

Tabla 03. Fuente: Banco de Datos Noche y Niebla, CINEP.

306 
La relación porcentual de estas modalidades se puede ver en la siguiente gráfica.

\section{Porcentaje de las modalidades de Violaciones a los} DD.HH cometidas por paramiltares en la región de influencia del bloque Elmer Cárdenas, 1994-2006

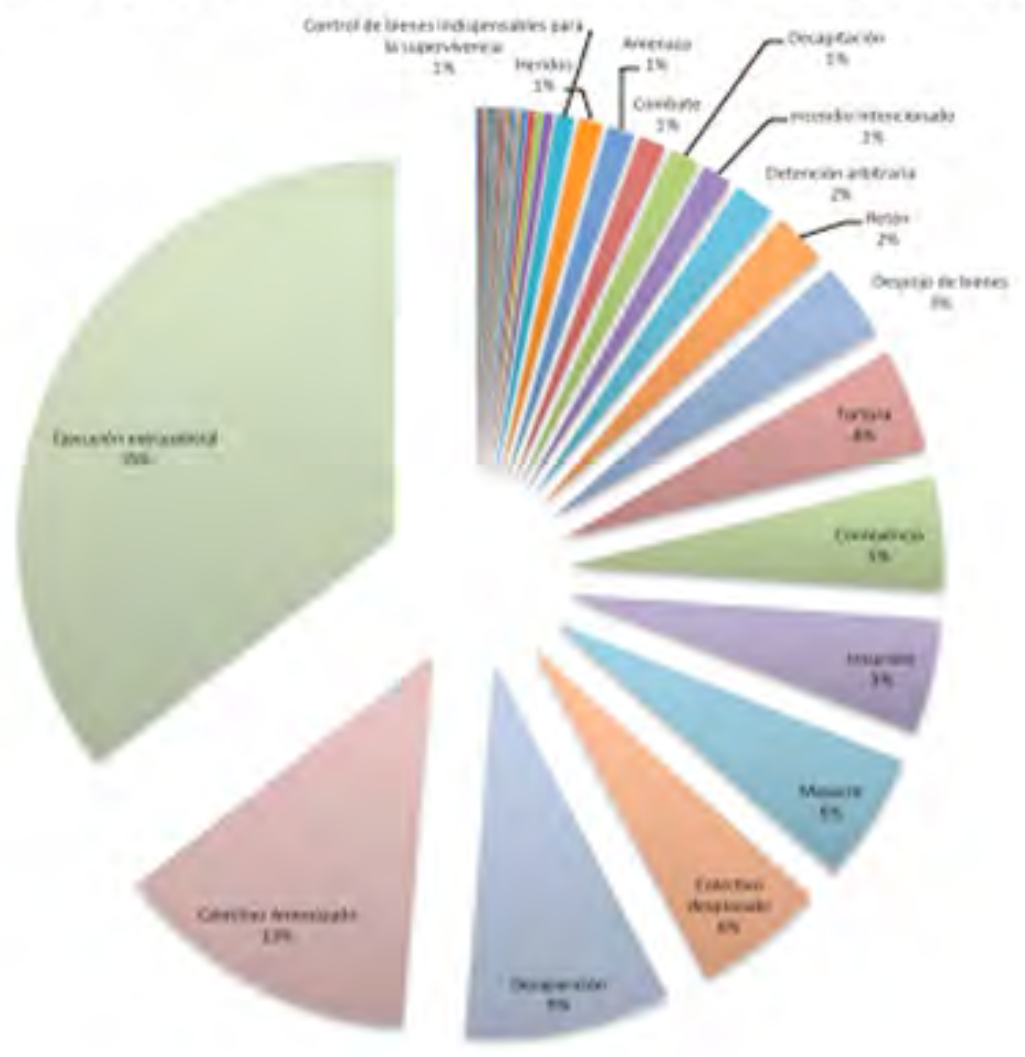

Gráfica 06. Fuente: Banco de Datos Noche y Niebla, CINEP. 
El desplazamiento forzado ha sido una de las consecuencias mas fuertes de la presencia paramilitar en la zona de estudio. Durante el periodo 1998/2006 enlos municipios donde hizo presencia el bloque Elmer Cárdenas se contabilizaron 150.098 personas expulsadas. E1 total municipal puede observarse en la siguiente tabla.

\begin{tabular}{|c|c|c|}
\hline Depto. & Municipios & $\begin{array}{l}\text { Total } \\
\text { Personas } \\
\text { Expulsadas } \\
\text { 1998-2006 }\end{array}$ \\
\hline \multirow{13}{*}{ } & Arboletes & 1996 \\
\hline & Cañasgordas & 2071 \\
\hline & Dabeiba & 12031 \\
\hline & Frontino & 11959 \\
\hline & Murindó & 1739 \\
\hline & Mutatá & 8729 \\
\hline & Necoclí & 3540 \\
\hline & Peque & 7338 \\
\hline & $\begin{array}{l}\text { San Juan de } \\
\text { Urabá }\end{array}$ & 1513 \\
\hline & Turbo & 17640 \\
\hline & Uramita & 2223 \\
\hline & Vigía del Fuerte & 5255 \\
\hline & subtotal & 76034 \\
\hline \multirow{13}{*}{ 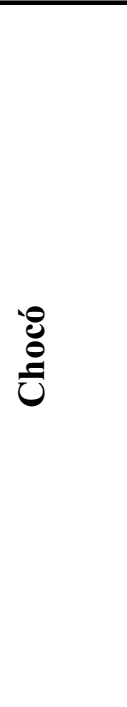 } & Acandi & 3.386 \\
\hline & $\begin{array}{l}\text { Bojaya } \\
\text { (bellavista) }\end{array}$ & 20.460 \\
\hline & Certegui & 19 \\
\hline & Condoto & 1.764 \\
\hline & Itsmina & 4.922 \\
\hline & Jurado & 2.254 \\
\hline & Medio san juan & 232 \\
\hline & Riosucio & 14.739 \\
\hline & Quibdo & 18.552 \\
\hline & Tado & 4.278 \\
\hline & Unguia & 4.232 \\
\hline & $\begin{array}{l}\text { Union } \\
\text { panamericana }\end{array}$ & 36 \\
\hline & subtotal & 74.874 \\
\hline & Total Región & 150.908 \\
\hline
\end{tabular}

Tabla 04. Fuente: Banco de Datos Noche y Niebla, CINEP.

308 
El comportamiento anual de la expulsión se presentó de la manera que ilustra la siguiente gráfica.

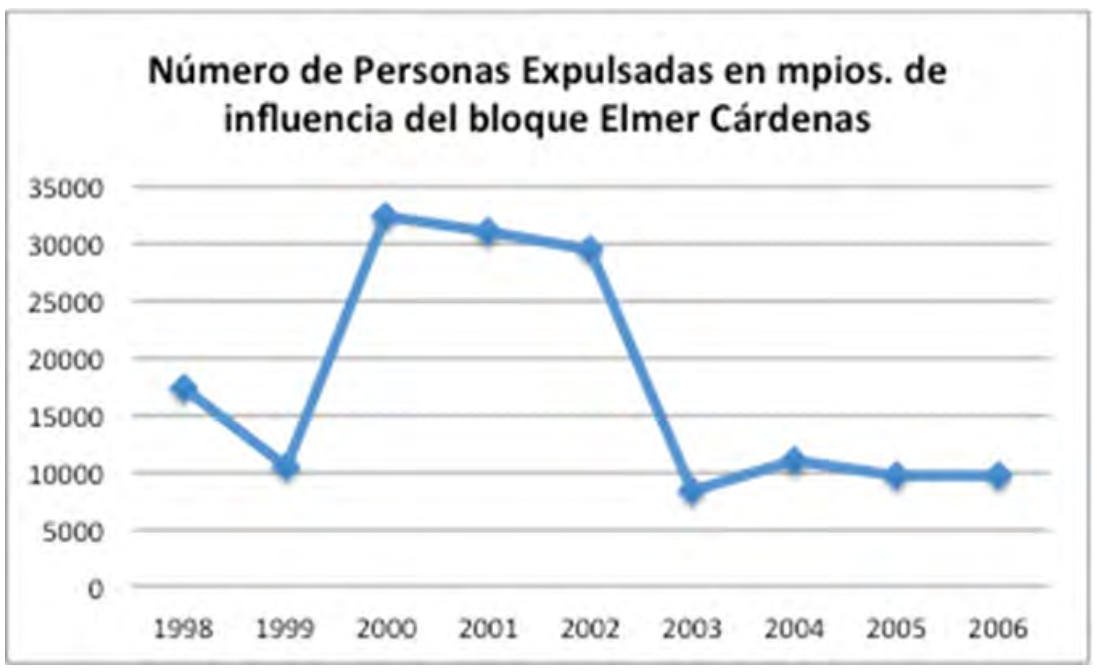

La distribución por subregión, a la hora de observar el total de personas desplazadas, observa un comportamiento diferenciado que permite advertir los impactos de las acciones paramilitares conforme estos empezaban a comprometer a nuevos municipios en dirección sur, es decir, desde el Urabá Hacia el Chocó.

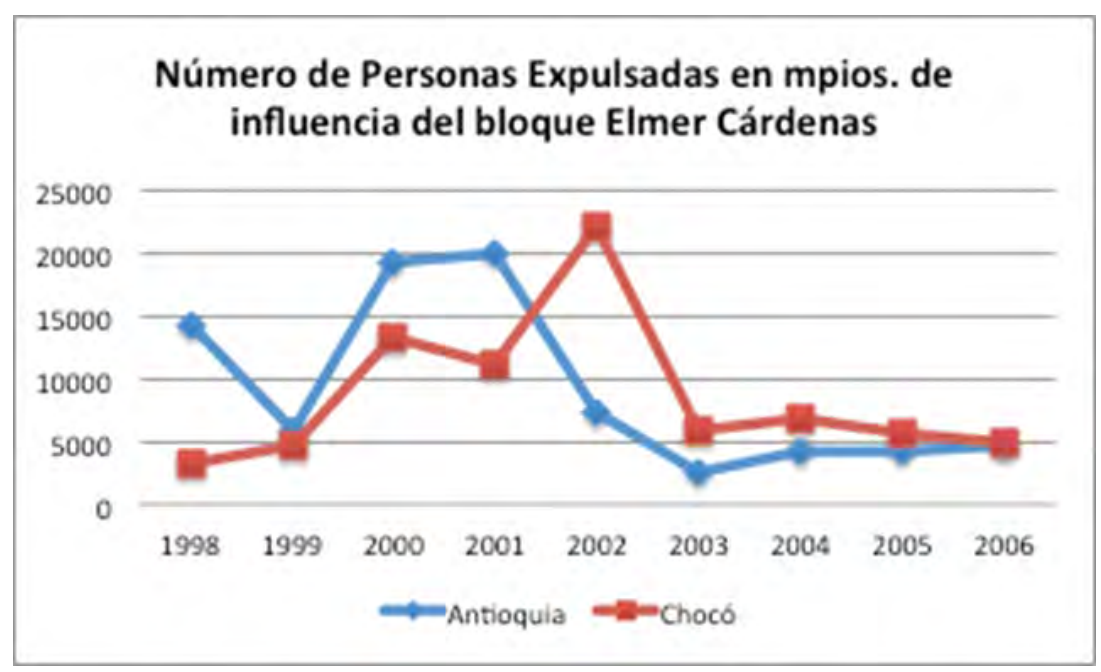

La expansión de los paramilitares desde el norte hacia el sur fue constatada en una investigación realizada por el INER en donde la mapificación de las acciones armadas demostró cómo estas fueron moviéndose, en intensidad y sobre el terreno, de norte a sur (véanse los siguientes mapas) $^{10}$. 


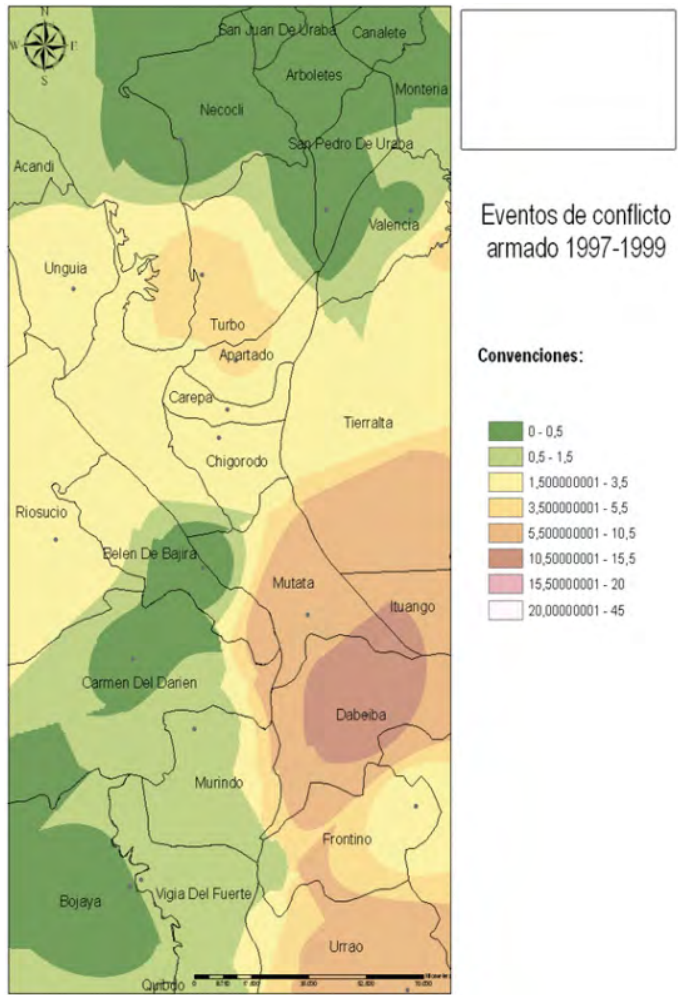

Mapa 01. Fuente: INER.

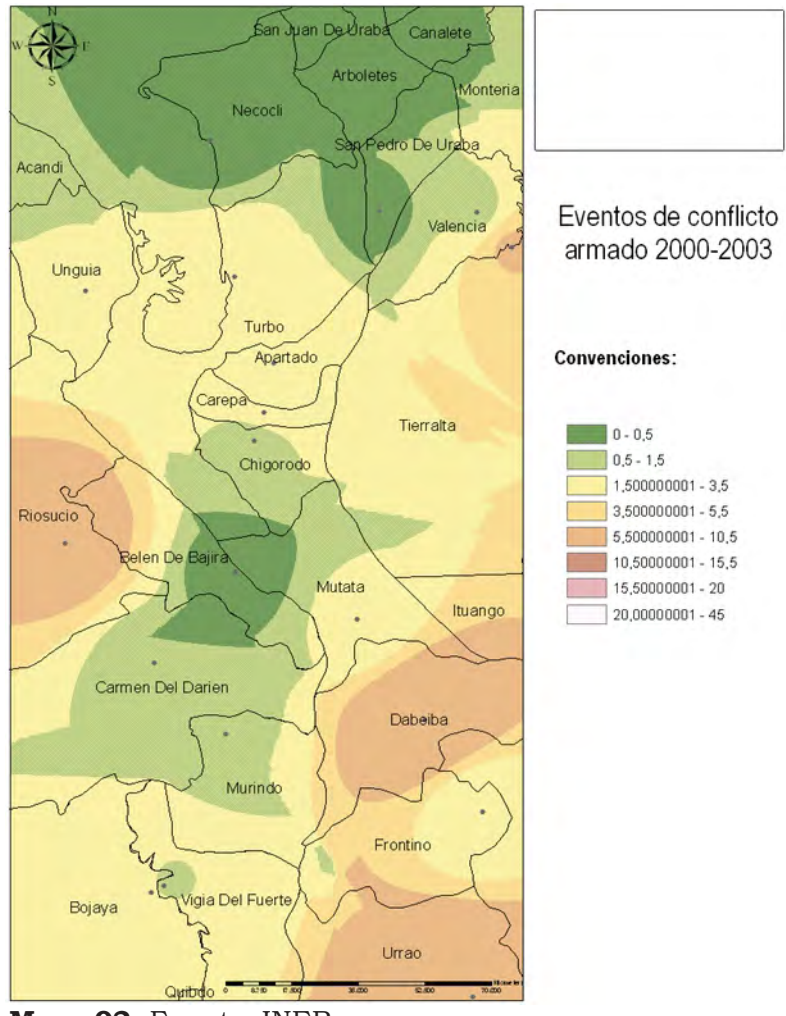

Mapa 02. Fuente: INER.

A continuación presentamos una serie de mapas que realicé a partir de la base de datos del Observatorio de DD.HH de la Vicepresidencia de la República en donde relacio las variables de Homicidios, Desplazamiento Forzado y el agregado de Acciones Armadas (que compendia aquellas de las Fuerzas Militares y grupos al margen de la ley) desde 1998 hasta 2006.

Esta serie de mapas coincide con la cartografia realizada por el INER en términos de la identificación del desplazamiento geográfico de la intensidad del conflicto desde el norte de la región (Urabá antioqueño) hacia el sur (chocó); intensidad que coincide con el despliegue paramilitar desde la zona de Córdoba y norte de Urabá hacia la zona sur de su área de influencia: Chocó. Los siguientes mapas permiten dimensionar los impactos de su expansión, en términos de acciones armadas registradas, desplazamientos forzados y número de homicidios ${ }^{11}$. 
Impactos del Paramilitarismo en la Región Urabá/Chocó 1998-2006. Claves para la Lectura de las Afectaciones Colectivas.
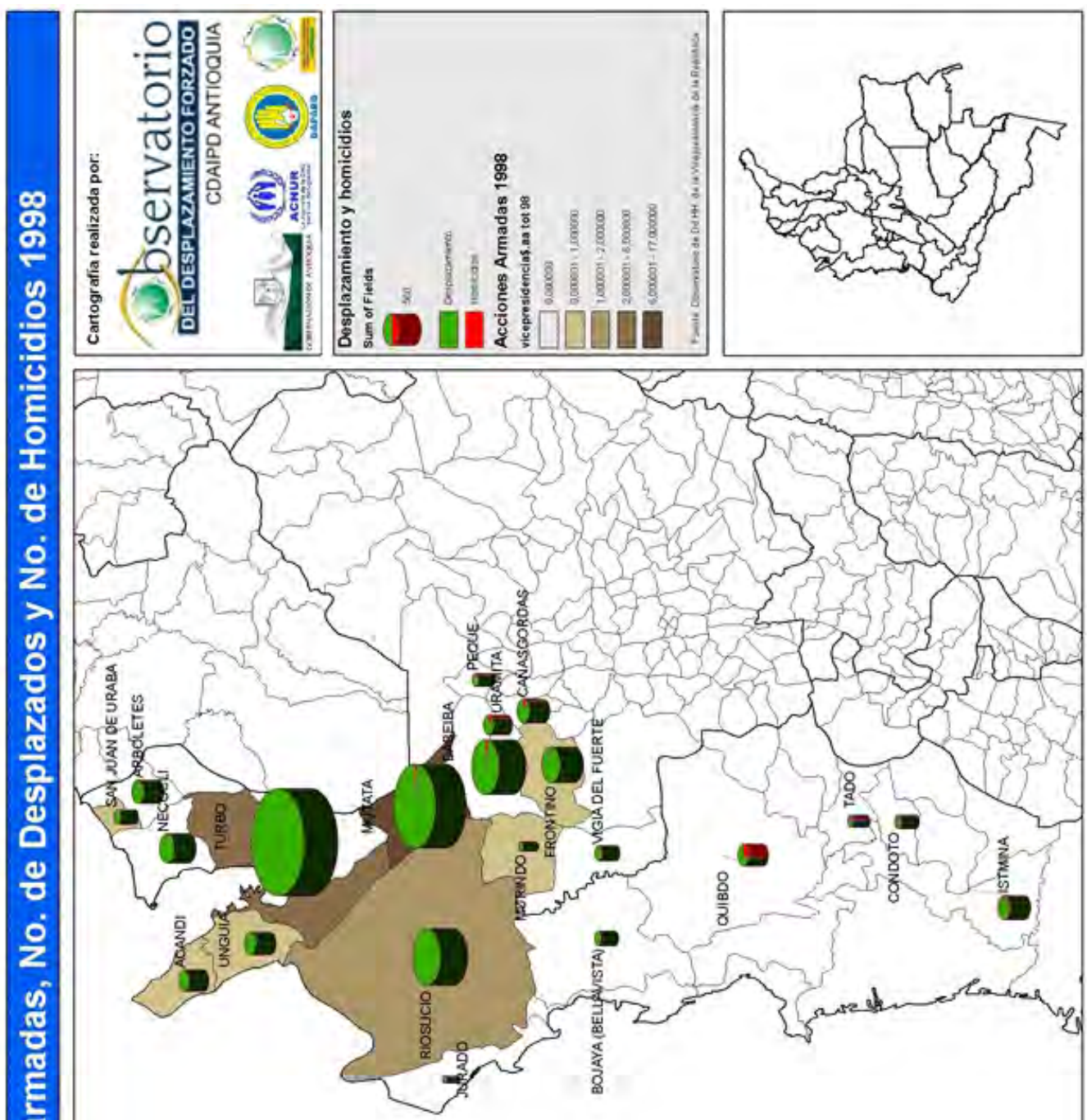

옹

Mapas 03. Fuente: Observatorio de Derechos Humanos de la Vicepresidencia de la República. Colombia. 
Impactos del Paramilitarismo en la Región Urabá/Chocó 1998-2006. Claves para la Lectura de las Afectaciones Colectivas.

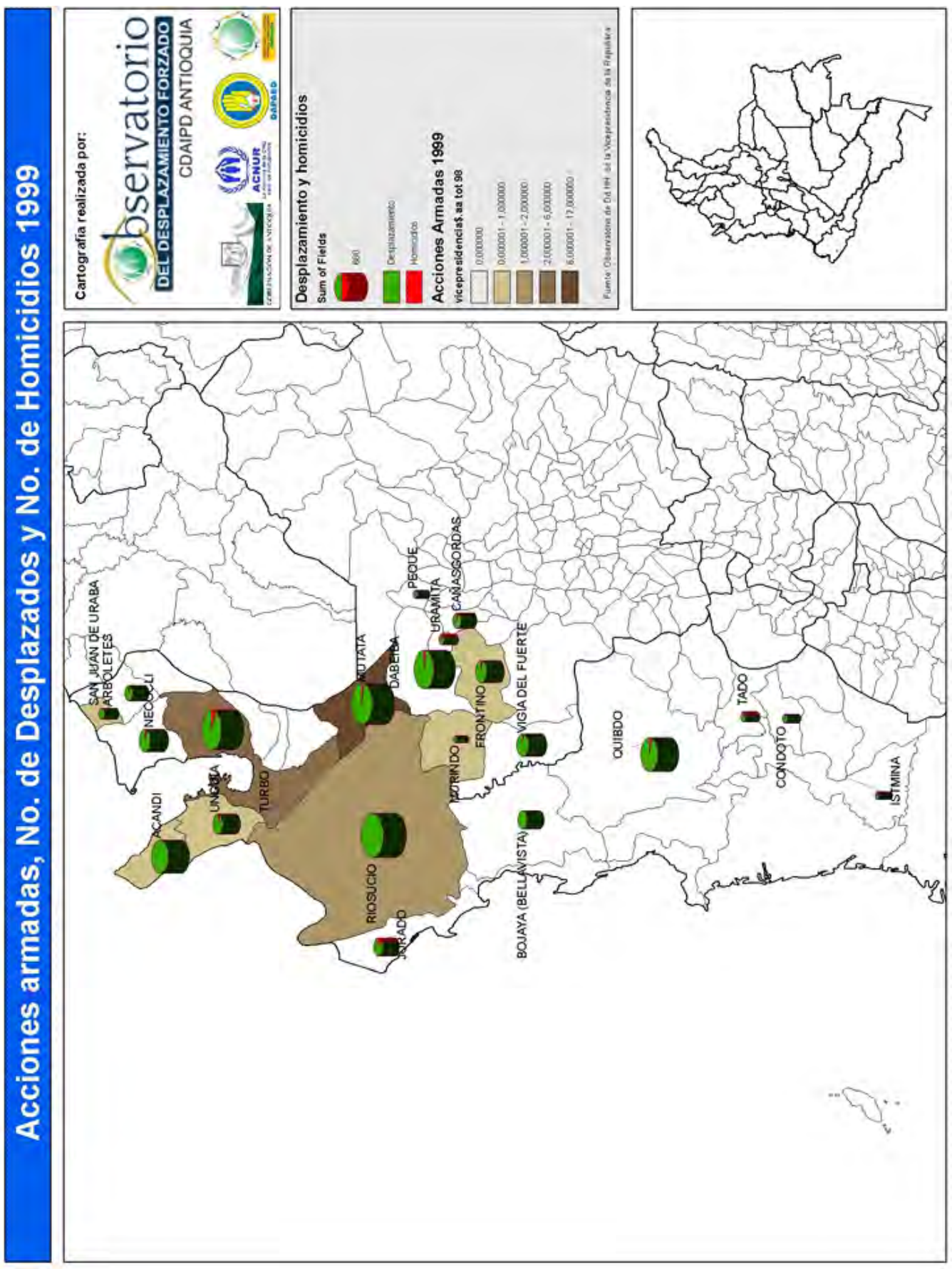

Mapas 04. Fuente: Observatorio de Derechos Humanos de la Vicepresidencia de la República. Colombia. 
Impactos del Paramilitarismo en la Región Urabá/Chocó 1998-2006. Claves para la Lectura de las Afectaciones Colectivas.
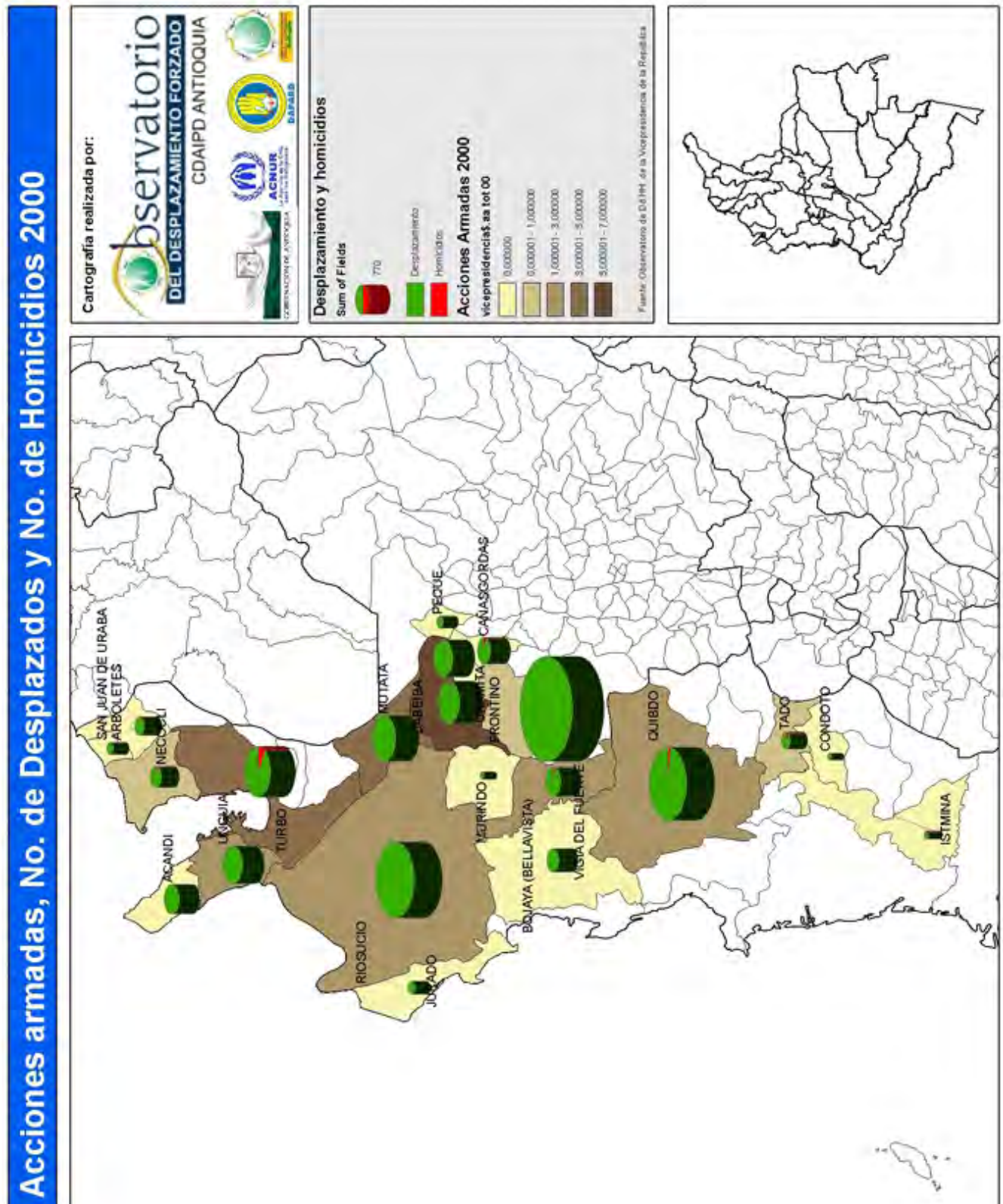

장 
Impactos del Paramilitarismo en la Región Urabá/Chocó 1998-2006. Claves para la Lectura de las Afectaciones Colectivas.

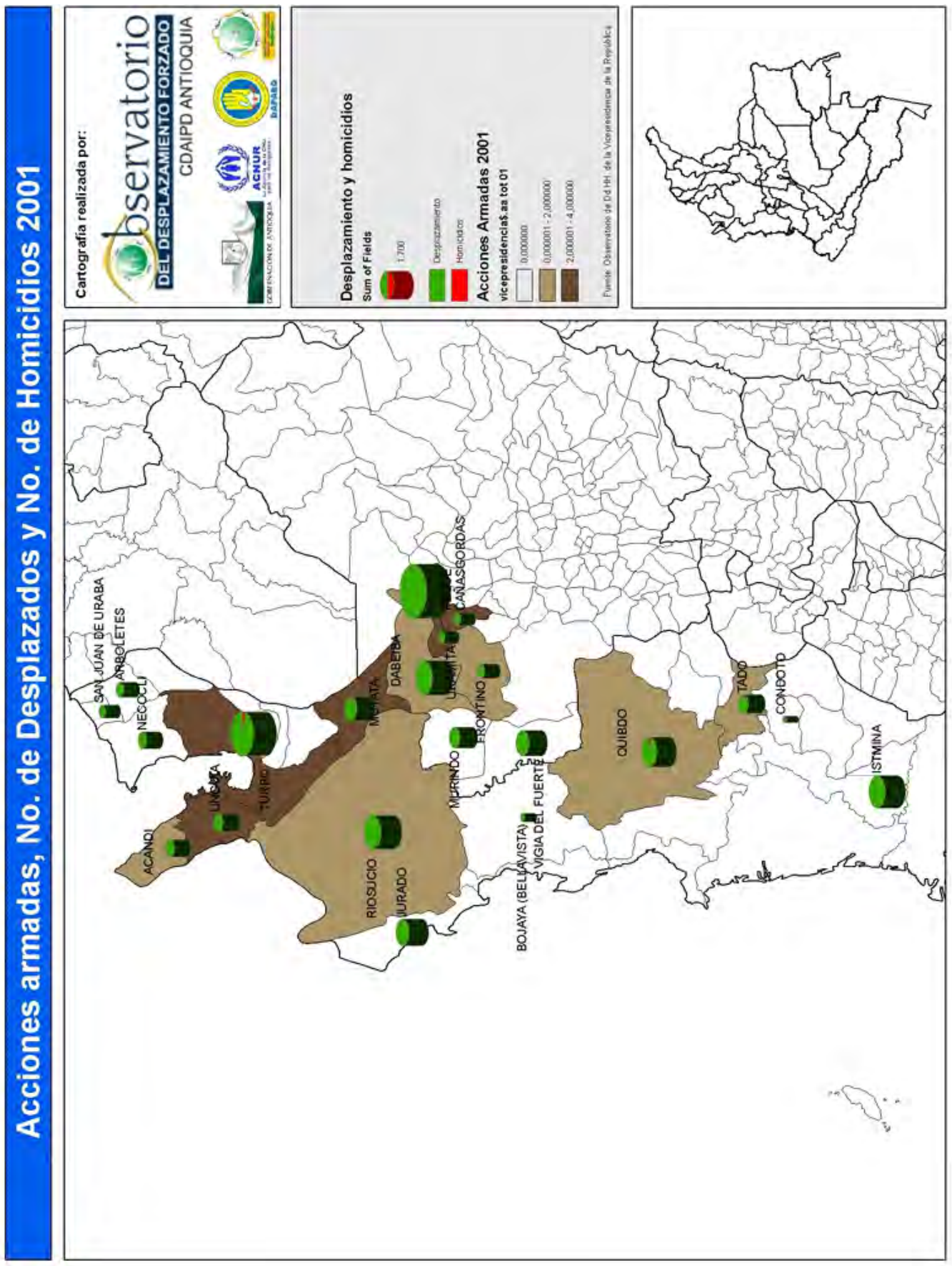

Mapas 06. Fuente: Observatorio de Derechos Humanos de la Vicepresidencia de la República. Colombia. 
Impactos del Paramilitarismo en la Región Urabá/Chocó 1998-2006. Claves para la Lectura de las Afectaciones Colectivas.

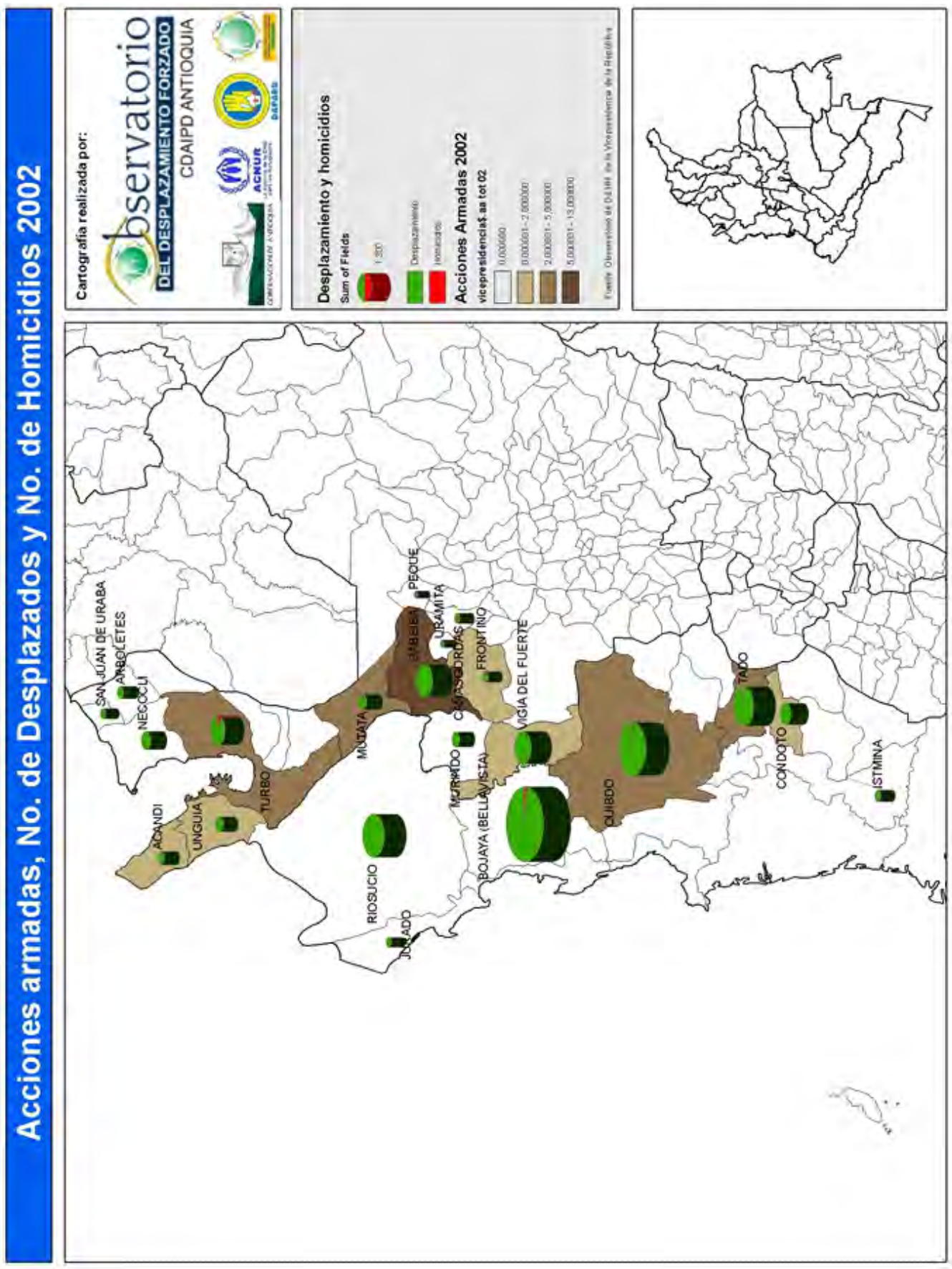

Mapas 07. Fuente: Observatorio de Derechos Humanos de la Vicepresidencia de la República. Colombia. 
Impactos del Paramilitarismo en la Región Urabá/Chocó 1998-2006. Claves para la Lectura de las Afectaciones Colectivas.

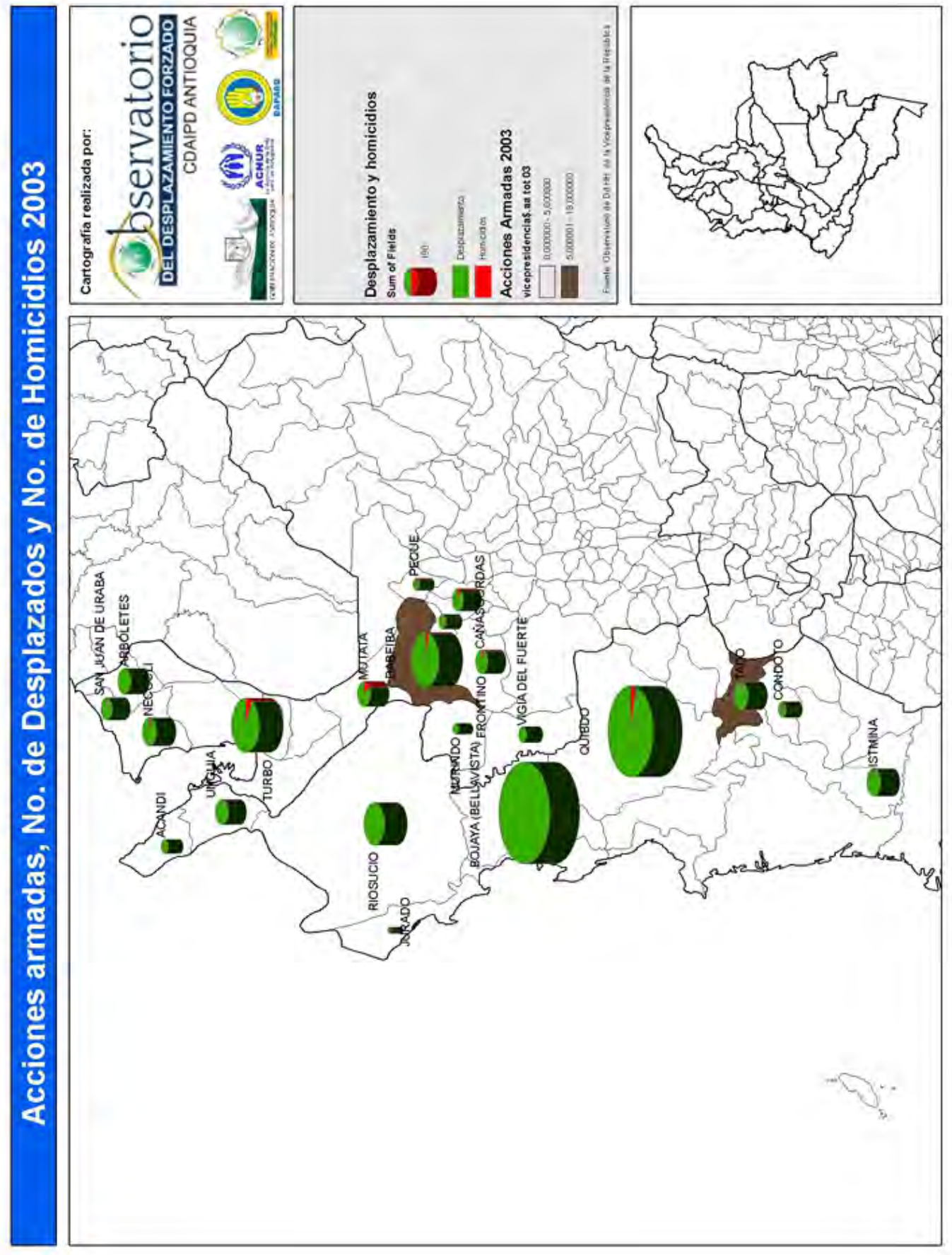

Mapas 08. Fuente: Observatorio de Derechos Humanos de la Vicepresidencia de la República. Colombia.

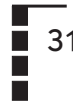
AGo.USB Medellín-Colombia V. $12 \quad N^{\circ} 2 \quad$ PP. 214- 547 Julio-Diciembre 2012 ISSN: 1657-8031 
Impactos del Paramilitarismo en la Región Urabá/Chocó 1998-2006. Claves para la Lectura de las Afectaciones Colectivas.

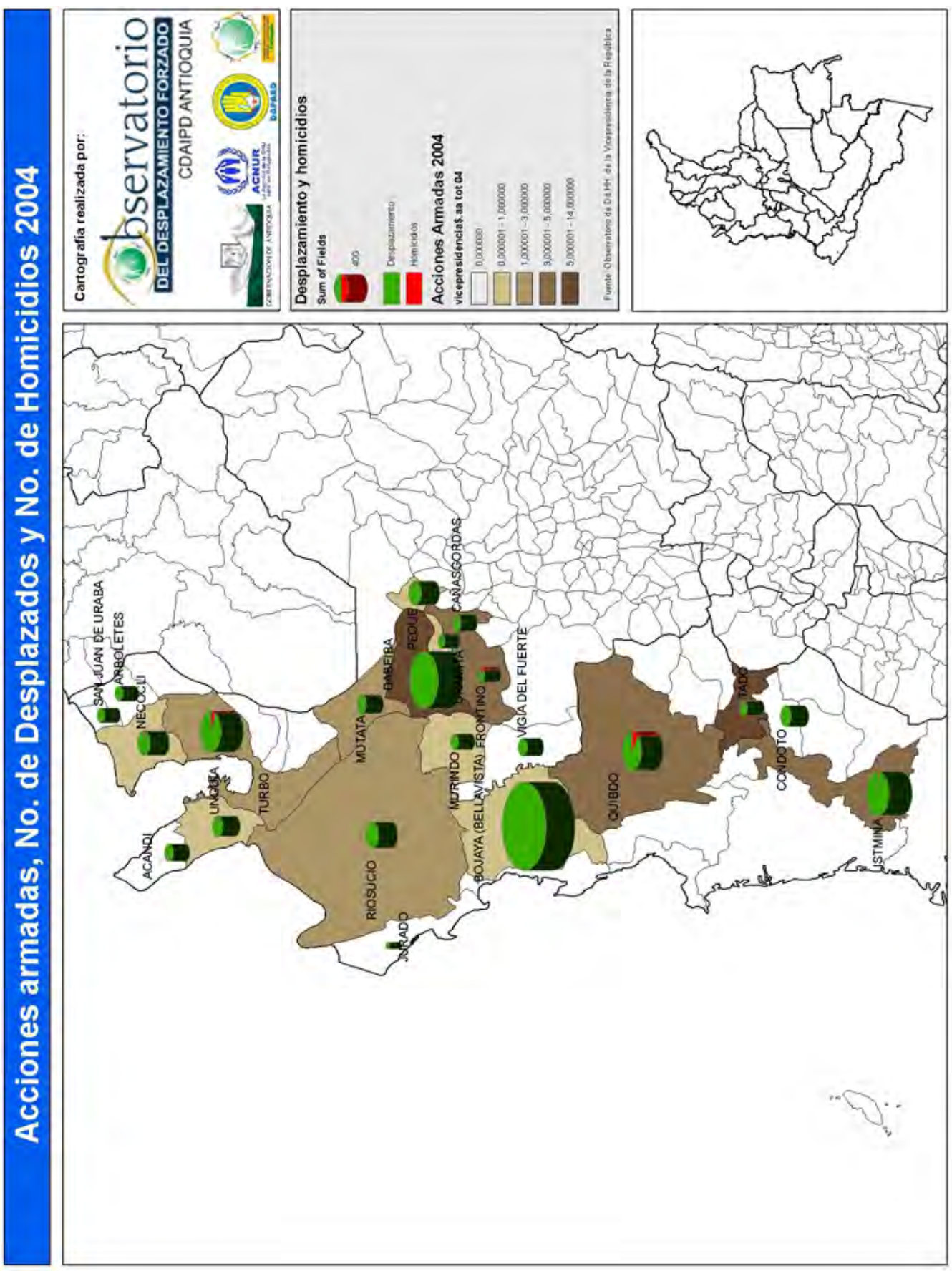

Mapas 09. Fuente: Observatorio de Derechos Humanos de la Vicepresidencia de la República. Colombia. 
Impactos del Paramilitarismo en la Región Urabá/Chocó 1998-2006. Claves para la Lectura de las Afectaciones Colectivas.

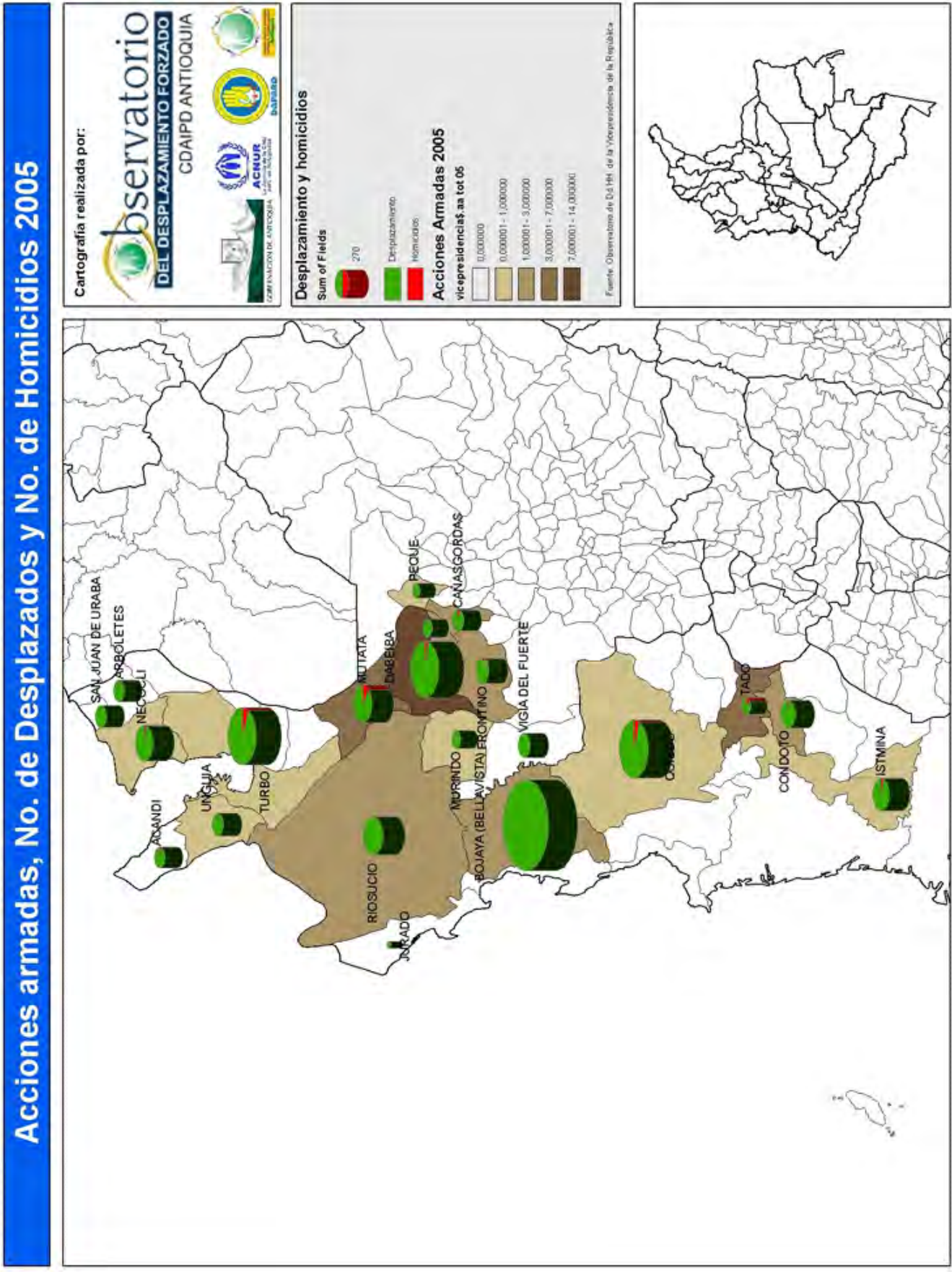

Mapas 10. Fuente: Observatorio de Derechos Humanos de la Vicepresidencia de la República. Colombia. 


\section{Acciones armadas, No. de Desplazados y No. de Homicidios 2006}

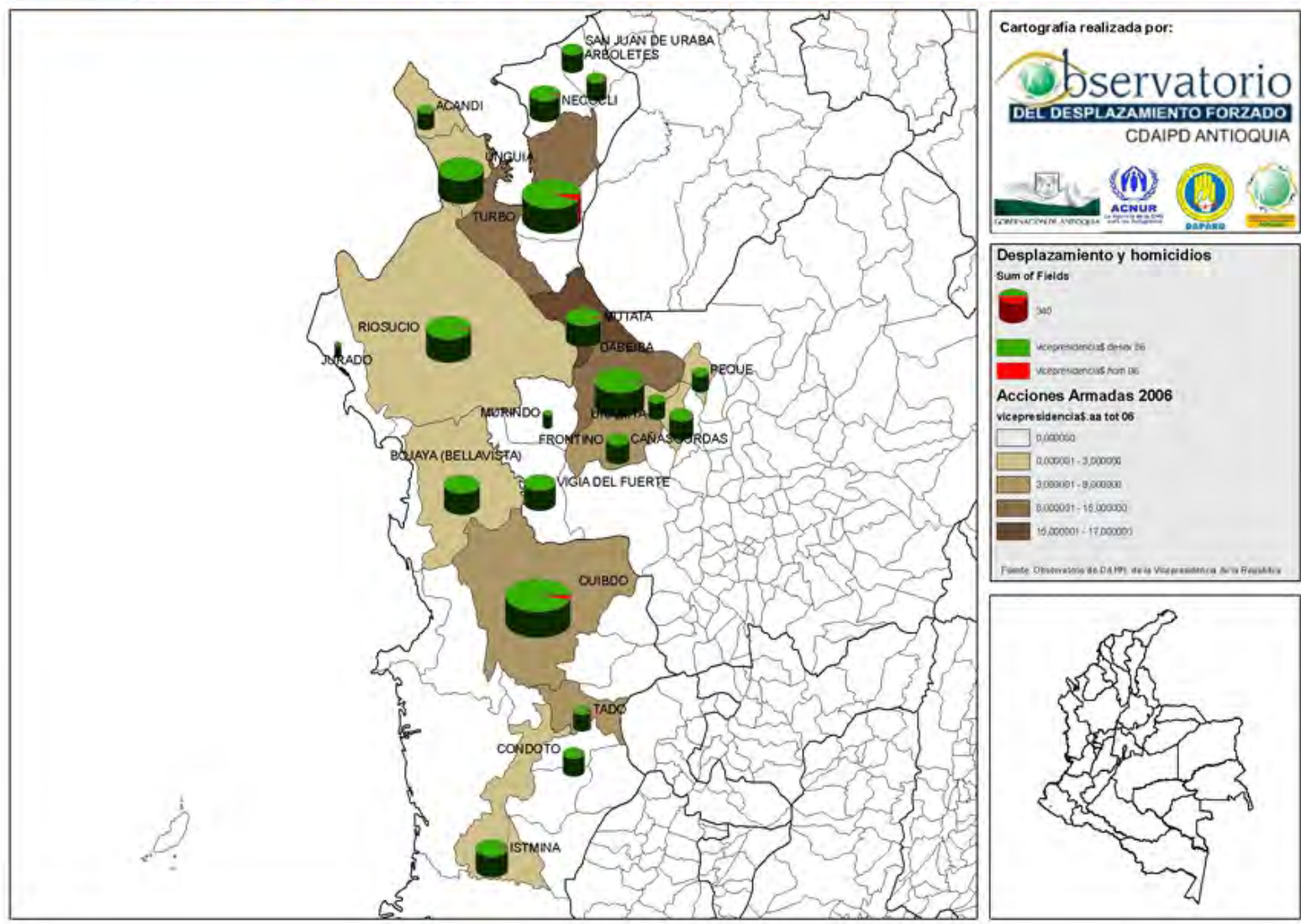

Mapas 11. Fuente: Observatorio de Derechos Humanos de la Vicepresidencia de la República. Colombia.

A partir de la información estadística analizada y cartografiada, las siguientes son algunas consideraciones claves que este ejercicio arroja sobre la naturaleza de las acciones paramilitares en la región de estudio.

1. Según fuentes oficiales (para este caso, los boletines diarios del DAS que procesa el Observatorio de DD.HH de la Vicepresidencia de la República) las acciones paramilitares en la región de estudio fueron mínimas. La magnitud de estos datos no coincide con la informes de prensa no con los datos manejados por fuentes no oficiales. El subregistro, por ende, es evidente.

2. Según la fuentes no gubernamental "Noche y Niebla", las acciones paramilitares en la región de estudio -durante el periodo 1994/2006- fueron 398. De este total se desagregan 786 modalidades de violaciones a los DD.HH. 
3. De ese total de acciones y modalidades, 11 eventos corresponden a eventos relacionados con enfrentamientos directos entre paramilitares y guerrilleros, es decir: tan solo el 2,5\% de las acciones totales. De igual forma, el 10\% de las acciones totales paramilitares denunciadas fueron registradas como actos de connivencia con miembros de fuerzas estatales (militares y policiales).

4. El $97,5 \%$ de acciones paramilitares se orientaron hacia la población civil. $20 \%$ de los eventos violatorios de los DD.HH tuvieron una directa afectación colectiva (amenazas y desplazamientos).

Cuarta parte. Las acciones paramilitares en la zona de estudio: entre la depredación económica y la fachada contrainsurgente.

En el marco de la ley de Justicia y Paz, el debate en torno a la posibilidad de otorgar algún tipo de reconocimiento político a los paramilitares fue zanjado por la Corte Constitucional al declarar inexequible el artículo 75 pues este asimilaba como políticos una serie de delitos comunes $^{12}$; no era procedente, en consecuencia, declarar sediciosos a los paramilitares pues no se han tratado de grupos que enfrenten al estado o se propongan derrocarlo para instaurar un nuevo régimen.

En medio de este debate uno de los apartados que se situó como relevante para reconocer carácter político a los paramilitares tuvo que ver con la naturaleza contrainsurgente de sus acciones. El trabajo de Edwin Cruz, "Los Estudios Sobre El Paramilitarismo En Colombia" (2007) recoge buena parte de las líneas discursivas que pretenden dar cuenta del paramilitarismo como fenómeno social. Una de ellas llama la atención, y es la que formula Alfredo Rangel, quien les denomina como "contrainsurgentes, civiles, autónomos del Estado, fuertemente penetrados por el narcotráfico y tienen estructuras muy complejas" (en Cruz 2007).

En el orden de cosas actual, cuando la negociación con los paramilitares culminó en la extradición de algunos de sus Líderes, la lentitud para hallar la verdad frente a un sinnúmero de hechos atroces, el reconocimiento contrainsurgente de "esos" paramilitares, los que negociaron con el estado, se da por descontado cuando de diferenciarlos de las "Bacrim" (bandas criminales, grupos herederos o rezagados de la negociación del gobierno Uribe con los grupos paramilitares) se trata. Los de antes, se supone, eran contrainsrugentes; los de ahora no son paramilitares porque no son contrainsurgentes.

Al respecto, y con el propósito de dimensionar la naturaleza de las acciones paramilitares en la zona de estudio que embarga a este documento, vale la pena llamar la atención sobre dos cosas:

1. No es nuestro propósito con este documento, pero bien cabe aclarar que la emergencia de las denominadas bandas criminales se deriva, entre otras cosas, de un proceso fallido de negociación que no logró desestructurar la maquinaria paramilitar ni las fuerzas sociales que le sustentaban. A diferencia de la negociación con los grupos guerrilleros en los años 90 (i.e. M-19, PRT, Corriente de Renovación Socialista...) que dieron por terminado sus estructuras militares, se sometieron a la justicia y entregaron sus armas, los paramilitares no entregaron su poderio.

320

AGO.USB Medellín-Colombia V. $12 \quad N^{\circ} 2$ PP. 214- 547 Julio-Diciembre 2012 ISSN: 1657-8031 
2. Recatamos las palabras del director de la Corporación Arcoiris, León Valencia, que señaló en un artículo publicado en la revista Semana en Febrero de 2011 que quienes establecen esa diferencia entre paramilitares contrainsurgentes y bandas criminales a secas:

No quieren aceptar que las actuales bandas son, en buena parte, continuidad de los paramilitares. Es el tercer error. El gobierno y los analistas que le son afines se han refugiado en este falso silogismo: los paramilitares que concurrieron a Santa Fe de Ralito tenían como propósito principal combatir a la guerrilla. No es este el objetivo de las bandas, luego a estas fuerzas no se les puede llamar paramilitares.

Las investigaciones académicas y judiciales de los últimos años han mostrado que los paramilitares dedicaron el 80 por ciento de sus energías al narcotráfico, a la usurpación de tierras y a la captura del poder local. Es lo que hacen las bandas. El discurso y la acción antisubversiva de aquellos eran más un ardid para legitimar sus atrocidades con la población civil que un grueso componente de su estrategia (2011).

Con este en mente bien vale la pena preguntarse: ¿la avanzada paramilitar en Urabá y Chocó correspondió a un ejercicio contrainsurgente? En la medida que los registros estadísticos y las versiones que han dado las víctimas -en su mayoría gente desplazada, perteneciente a comunidades campesinas, indigenas y afrocolombianas- dan cuenta del destierro, del despojo de tierras y de la implantación de modelos económicos que riñen con las tradiciones territoriales, esto poco tiene que ver con la idea de la lucha contraguerrillera.

A pesar del subregistro de datos sobre el conflicto armado en la región y aunque la base de datos Noche y Niebla no se trate de información oficial, los testimonios, denuncias y versiones que aparecen compendiadas en el Banco de Datos dan cuenta de una rapacidad criminal que en aras de la concentración de tierras, la explotación de recursos mineros y naturales así como la cooptación de la política local (y por ende, el manejo de recursos públicos) implicó que los paramilitares no escatimaran sus recursos de terror; no por nada uno de los nombres que asumieron en la región fue el de "mochacabezas" y una de sus prácticas mas extendidas consistió en juegos de futbol con cabezas de sus víctimas, muchas veces niños.

Ejercicios de sistematización de este tipo permiten dimensionar no solo el carácter de las acciones paramilitares sino su orientación: aterrorizar a la población civil, plegarlas a su control y someterlas a sus designios económicos.

Una de estas intervenciones paramilitares en la región, quizá la de mayor impacto socioeconómico sobre comunidades indígenas y afrocolombianas, tuvo que ver con el agenciamiento de la extensión de cultivos de palma y banano en las inmediaciones del río Atrato de parte no solo de empresas propias de los paramilitares sino de empresas de carácter nacional e internacional. Según la Comisión Intereclesial Justicia y Paz:

En el caso del Bajo Atrato, ese reinado del progreso se ha cimentado en el despojo de 15 caseríos en el Curvaradó de más de 25 mil hectáreas y en el Cacarica de 20 mil hectáreas y 4 caseríos, que fueron titulados colectivamente por gobiernos anteriores ${ }^{13}$. 
El trabajo "La memoria desde las víctimas II. Chocó: por los hijos y la tierra despojada (Curvaradó, 1996-2002)" financiado por el Gobierno Español y realizado por la Corporación Nuevo Arcoiris recoge testimonios como el de un campesino llamado don Pedro, quien junto a su familia salieron desplazados de la región tras la masacre de Las brisas en febrero de 1996. A su regreso, dice el informe, la tierra de don Pedro y su familia.

Actualmente se encuentra sembrada de palma africana. Esta tierra parece irrecuperable ya que, si bien Pedro posee el título de su terreno, hacia 1998 llegó una empresa norteamericana llamada unión de Cultivadores de palma de Aceite en el Urabá, Urapalma, y otras empresas tales como Palmas de Curvaradó, Palmas S.A., Palmura y Palmadó entre otras, las cuales extendieron el proyecto de palma africana en la zona de Curvaradó, incluyendo el territorio que una vez perteneció a Pedro, y la zona de Jiguamiandó en el bajo Atrato chocoano.

Uno de los casos emblemáticos es el de Urapalma, una empresa que -según información publicada por El Espectador- tiene:

Hectáreas sembradas con cultivos de palma en un territorio que el Estado legalmente adjudicó a las comunidades negras desplazadas del Chocó, y cuya gestión ha sido objeto de cuestionamientos tanto de los organismos de control en Colombia, como de la Corte Interamericana de Derechos Humanos, también financia su controvertido negocio con recursos provenientes del Banco Agrario y ayudas aprobadas por el Congreso de los Estados Unidos ${ }^{14}$.

El papel jugado allí por los paramilitares fue definido por uno de sus comandantes, Jhon Fredy Rendon Herrera, como forma para recibir el apoyo de empresarios agrícolas hay algunos terratenientes que durante el conflicto compraron muchísimas tierras muy baratas, y que además fueron nuestro apoyo económico porque nosotros siempre nos financiamos de las grandes cadenas de la producción de la económica, como el banano, el plátano la ganadería. Pero en la región se adquirieron muchas tierras que se dice compraron las autodefensas. La realidad es que se quedaron con ellas los que iban detrás de nosotros "palmoteándonos"15.

El portal Verdad Abierta relaciona los impactos de los paramilitares de Rendón con estrategias de autojustificación para salvar responsabilidaes en la medida que Rendón no reconoce como nocivo este despojo sino todo lo contrario, como una apuesta por el desarrollo. Dice el portal:

Las miles de hectáreas sembradas con palma africana en las márgenes de los ríos Opogadó, Napipí y Bojayá entre otros, se dice que pertenecen a "El Alemán". Sus hombres asesinaron y desplazaron a cientos de indígenas y afrodescendientes que se negaron a vender sus tierras para sembrar palma. Las comunidades de Curvaradó, Cacarica y Domingodó, hablan de por lo menos 22.000 hectáreas que les han sido arrebatadas por los hombres del Bloque Elmer Cárdenas. La zona de Belén de Bajirá en Mutatá también registra miles de hectáreas sembradas con palma, las cuales también se dice fueron tomadas por el Bloque Élmer Cárdenas, y por Vicente Castaño, tras obligar a cientos de campesinos a entregarle sus territorios. Sin embargo, todo este despojo ha sido presentado por "El Alemán" y los hombres de su Bloque como un proyecto de envergadura social llamado PASO, y que busca generar empresas productivas en zonas alejadas. En realidad, es parte de una estrategia de 
repoblamiento y control territorial cuyo eje es una agroindustria maderera y palmífera diseñada por Vicente Castaño.

Por eso "El Alemán" insiste en sus versiones libres que él simplemente actuaba como líder comunitario. "Nosotros entramos en mayo 28 de 2002 a Bajirá, y en reuniones con el padre Leonidas Moreno y Monseñor García, se acordó que esas tierras eran de los nativos. En consecuencia, no soy propietario de tierras con cultivos de palma ni a mi nombre ni por testaferros. Esos cultivos son de empresarios bananeros. Yo solo me limité a presentar la propuesta a Jaime Sierra, gerente de empresas palmeras" dijo en su versión libre ${ }^{16}$.

\section{Conclusiones.}

A partir de estos elementos aquí resaltados, y los casos compendiados en la sistematización del Banco de Datos "Noche y Niebla" del CINEP me es posible proponer que las afectaciones colectivas implican, entre otras, las siguientes consideraciones:

1. Las acciones de los paramilitares en la zona de estudio estuvieron, en un altísimo porcentaje, dirigidas principalmente (antes que combatir a la guerrilla) contra la población civil.

2. Estas acciones estuvieron orientadas a promover proyectos económicos, bien fuera de los dueños de los ejércitos privados o de agentes externos a la región (nacional o internacional) afines a los métodos y objetiva de los paramilitares.

3. Esta reconfiguración política de la región se sustentó a partir del destierro de la población, el despojo de sus tierras y bienes, el disciplinamiento de sus acciones y comportamientos; la cooptación de los poderes locales y la cercenación de los liderazgos comunitarios.

4. Una de las consecuencias que las acciones paramilitares han dejado en el territorio tienen que ver, en consecuencia, con la instauración de un modelo de desarrollo económico que responde a intereses externos a la región y que se sustenta en impresentables crimenes de lesa humanidad.

5. Otra de las consecuencias visibles hoy día tiene que ver con las subjetividades de los habitantes de la zona y sus modelos de socialización. En la medida que el Banco de Datos "Noche y Niebla" da cuenta de las modalidades de violaciones a los DD.HH cometidos por los paramilitares, es posible considerar que el tejido social comunitario ha sido uno de los elementos de mayor afectación. Esto implica que la reconstrucción de formas de organización comunitaria, de socialización, de participación y de relación con el estado se han visto mediados por las acciones paramilitares.

6. La victimización generalizada de la población implica, entonces, un enorme reto para recuperar no solo el tejido social sino también el orden territorial de la región. 
7. Sin un desmonte efectivo de la estructura paramilitar y una clara definición de las fuerzas sociales que le auparon, los agentes económicos que les instigaron y los miembros del estado que les acolitaron resultará imposible un proceso de verdad que permita la justicia y la efectiva reparación.

8. Esto último es vital y capital para reconstruir el papel del estado en la región y su relación con las comunidades, pues mientras la legitimidad del estado no pase por un prácticas que mediante el ejercicio concreto del poder garanticen que exista el reconocimiento de la justicia, la legalidad y la legitimidad de sus acciones, las garantías de no repetición quedarán en entredicho. 


\section{Referencias.}

Balbin , J., \& Insuasty Rodriguez, A. (2010). Las Victimas en Contextos de Violencia e Impunidad: Caso Medellín. Medellin: Instituto Popular de Capacticación.

Balbin, J., \& Insuasty Rodriguez, A. (2009). Victimas, Violencia y Despojo. Medellin: Litoimpacto.

Botero, F. (1990). Urabá : colonización, violencia y crisis del estado. Medellin: CIE.

CINEP. (1 de Julio de 2012). Noche y niebla. Obtenido de www.nocheyniebla.org.

CNAI. (2007). La memoria desde las víctimas II. Chocó: por los hijos y la tierra despojada (Curvaradó, 1996-2002). Bogota: AECI.

CNRR. (4 de Octubre de 2005). Declaraciones Eduardo Pizarro Leóngomez al término de la instalación de la comisión nacional de reparación y reconciliación. Obtenido de cnrr.org: http://www.cnrr.org.co/contenido/09e/spip.php?article283.

Cruz, E. (2007). Estudios sobre el paramilitariso en colombia. anal.polit, 20(60), 117-134.

Espinosa, N., Gomez, S., \& Monsalve, J. (2011). Atlas del conflicto armado en Antioquia 1985-2010. Obtenido de Instituto de Estudios Regionales: http://iner.udea.edu.co:3000/.

Garcia, C. I. (1996). Urabá. Región, actores y conflicto. 1960-1990. Bogota: CEREC.

Garcia, C. I. (1998). Antioquia en el marco de la guerra y la paz. Transformaciones. De la lógica de los actores armados. Bogota: CINEP.

Garcia, C. I. (1998). Características y dinámica de la movilización social en Urabá. Bogota: CV Editores.

Giraldo , A., Gomez, S., \& Espinosa, N. (2007). Geografia de las movilidades poblacionales en Antioquia”. Medellin: Departamento de Antioquia.

Rangel, A. (2005). El poder paramilitar. Bogota: Editorial Planeta.

Uribe, M. T. (2000). El desplazamiento forzado en Antioquia. Medellin: IEP.

Villegas, L. (1995). Atlas del Poblamiento en Antioquia. Medellin: Informe de investigacion. Universidad de Antioquia. 
${ }^{2}$ Este artículo hace parte del planteamiento del proyecto de investigación "Exploración de las condiciones, características y dimensiones que hacen de las afectaciones derivadas del conflicto armado, un daño colectivo: propuesta para la formulación de una metodología de análisis", inscrito ante la dirección de investigaciones de la Universidad San Buenaventura. La propuesta la realicé gracias al apoyo del Observatorio del Desplazamiento Forzado de la Gobernación de Antioquia, quienes me permitieron acceder a sus bases de datos y utilizar sus recursos tecnológicos para la elaboración de la cartografia aquí dispuesta. Mediante la investigación que he mencionado me propongo establecer qué condiciones, características y dimensiones hacen de las afectaciones derivadas del conflicto armado, un daño colectivo. Una versión preliminar de este artículo hace parte de los documentos producidos por el Observatorio del Desplazamiento Forzado que pueden ser consultados en su página web: http://oddifantioquia.org/.

${ }^{3}$ Este y todos los mapas fueron realizados por el Autor y hacen parte del archivo del Observatorio Departamental del Desplazamiento Forzado que pueden ser consultados en su página web: http://oddifantioquia.org/.

${ }^{4}$ Este portal, dice su página web, “ nació en 2008, cuando la Fundación Ideas para la Paz (FIP), un centro de pensamiento independiente y la revista SEMANA, resolvieron unir las fortalezas del periodismo y de la investigación académica para contribuir de alguna manera significativa a develar la verdad y a reconstruir la memoria histórica sobre el conflicto armado colombiano de los últimos años". Véase: www.verdadabierta.com.

${ }^{5}$ Véase: "Bloque Elmer Cárdenas de Urabá" En:

http:/ / www.verdadabierta.com/victimarios/los-bloques/416-bloque-elmer-cardenas-deuraba-.

${ }^{6}$ Cfr. Monografias Regionales. Anexo de la investigación "Geografía de las Movilidades Poblacionales en el departamento de Antioquia” (Giraldo, Gómez y Espinosa 2007).

7 Véase: "Farc contraatacan en la llorona". EL Tiempo, 14 de abril de 1999 www.eltiempo.com/archivo/documento/MAM.

${ }^{8}$ Para observar el comportamiento en las cifras del conflicto, véase el trabajo antes citado de Giraldo, Gómez y Espinosa (2005); Cifras y estadísticas mas actualizadas a partir de las base SARAC del CERAC en el trabajo de ODECOFI (2011) o cifras actualizadas sustentadas en el Observatorio de la Vicepresidencia y Noche y Niebla en Espinosa y Gómez (2011).

${ }^{9}$ La autora señala que para la segunda etapa los conflictos que predominaron fueron: entre quienes se disputan la tierra; entre trabajadores bananeros y empresarios; entre estado y guerrillas; entre guerrillas; entre la Unión Patriótica y Esperanza Paz y Libertad; entre reinsertados y guerrillas; entre paramilitares y guerrillas.

${ }^{10}$ Tomados de Odecofi 2011. 
${ }^{11}$ Cabe anotar que el mapa del año 2003 presenta problemas de subregistro en el número de acciones armadas.

${ }^{12}$ Una reseña de este debate puede leerse en el artículo periodístico de César Paredes “ ¿Sí es posible concederles estatus político a los paramilitares?” publicado en la revisa Semana el 26 de julio de 2007. Disponible en: http://www.semana.com/on-line/posible-concederlesestatus-politico-paramilitares / 105206-3.aspx.

${ }^{13}$ Véase: CIJP "Agronegocios de palma y banano en el Bajo Atrato Impactos ambientales y socioeconómicos”. www.pasc.ca/IMG/doc/Palma_y_bio.doc.

${ }^{14}$ Véase: “Dinero gringo a cultivos en líos”. El Espectador, septiembre de 2006.

${ }^{15}$ Tomado de CNAI 2007 (Ibid). “El paso del alemán”, en Urabá hoy, no 34.

${ }^{16}$ Véase: "Bloque Elmer Cárdenas de Urabá" En:

http:/ / www.verdadabierta.com/victimarios/los-bloques/416-bloque-elmer-cardenas-deuraba-. 